\title{
The mechanism of root growth inhibition by the endocrine disruptor bisphenol A (BPA)
}

Ramin Bahmani $^{1,2,3, \mathrm{I}}$, DongGwan Kim ${ }^{1,2,3, \mathrm{I}}$, Mahsa Modareszadeh ${ }^{1,2,3}$, Andrew J Thompson ${ }^{4}$, Jeong Hoon Park ${ }^{5}$, Hye Hyun Yoo $^{5}$ and Seongbin Hwang ${ }^{1,2,3 *}$

Department of Molecular Biology ${ }^{1}$, Department of Bioindustry and Bioresource Engineering ${ }^{2}$, and the Plant Engineering Research Institute ${ }^{3}$, Sejong University, Seoul, 143-747, KOREA; C ranfield Soil and Agrifood Institute ${ }^{4}$, Cranfield University, Cranfield, Bedfordshire MK43 0A L, UK; College of Pharmacy ${ }^{5}$, Hanyang University, Ansan, Gyeonggi-do 15588, Korea

${ }^{\mathrm{I}}$ Equal contribution

* Correspondence: Seongbin Hwang. Department of Molecular Biology, Department of Bioindustry and Bioresource Engineering, and the Plant Engineering Research Institute, Sejong University, Seoul, 143-747, KOREA. E-mail address: sbhwang@sejong.ac.kr. 


\begin{abstract}
Bisphenol A (BPA) is a harmful environmental contaminant acting as an endocrine disruptor in animals, but it also affects growth and development in plants. Here, we have elucidated the functional mechanism of root growth inhibition by BPA in Arabidopsis thaliana using mutants, reporter lines and a pharmacological approach. In response to $10 \mathrm{ppm} \mathrm{BPA,} \mathrm{fresh} \mathrm{weight} \mathrm{and}$ main root length were reduced, while auxin levels increased. BPA inhibited root growth by reducing root cell length in the elongation zone by suppressing expansin expression and by decreasing the length of the meristem zone by repressing cell division. The inhibition of cell elongation and cell division was attributed to the enhanced accumulation/redistribution of auxin in the elongation zone and meristem zone in response to BPA. Correspondingly, the expressions of most auxin biosynthesis and transporter genes were enhanced in roots by BPA. Taken together, it is assumed that the endocrine disruptor BPA inhibits primary root growth by inhibiting cell elongation and division through auxin accumulation/redistribution in Arabidopsis. This study will contribute to understanding how BPA affects growth and development in plants.
\end{abstract}

Keywords: auxin, bisphenol A, cell division, cell elongation, ethylene, root

\title{
Summary statement:
}

Endocrine disruptor BPA inhibits primary root growth by reducing cell division in meristem zone and cell elongation in elongation zone through auxin accumulation and distribution. 


\section{Introduction}

Environmental and agricultural contamination with endocrine disruptors such as bisphenol A (BPA; 2,2-bis(4-hydroxyphenyl)propane) have gained considerable global attention in recent years due to the high potential risk that they pose to the environment, ecosystems and human health (Hunt et al., 2009; Wee and Aris, 2017). Endocrine-disrupting compounds (EDCs) are any chemical compounds that are able to emulate endocrine hormones or act as hormone analogues to interrupt normal hormonal functions. BPA is known as an estrogenic EDC and has been used in the production of various consumer durables, such as polycarbonate, polyacrylate, clear plastic, beverage and food cans and medical equipment (Cooper et al., 2011; Goodson et al., 2002). The annual production of BPA is estimated at 3.7 million tons worldwide (Mihaich et al., 2009). Given that BPA can be released to the soil from different sources, such as wastewater effluents and sewage sludge (Flint et al., 2012; Meesters and Schroder, 2002), plants may face a BPA challenge during their lifespan. Despite many reports regarding the effect of BPA on animals (Canesi and Fabbri, 2015; Flint et al., 2012), relatively little is known about the response of plants to BPA exposure.

According to previous reports, BPA has been found to affect plants in a dose-dependent manner. For example, $1 \mathrm{ppb}$ to $1 \mathrm{ppm}$ BPA positively affects the growth of soybean (Glycine max) and the shoot differentiation of carrot (Daucus carota) calli (Terouchi et al., 2004). In contrast, BPA was toxic to broad bean (Vicia faba L.), tomato (Solanum lycopersicum L.), durum wheat (Triticum durum Desf.) and lettuce (Lactuca sativa L.) at concentrations of 10-50 ppm (Ferrara et al., 2006). A low concentration of BPA (1.5 ppm) enhanced the growth of soybean seedlings, but at higher concentrations (7-50 ppm), it decreased growth, photosynthetic rate and chlorophyll content (Qiu et al., 2013). Exposure of Arabidopsis thaliana seedlings to 1-5 $\mu \mathrm{M}$ BPA (0.23-1.14 ppm) increased root length, lateral root formation and fresh weight, whereas values for these traits were reduced at 10-25 $\mu \mathrm{M}$ (2.28-5.7 ppm) (Pan et al., 2013). 
Higher concentrations of BPA (over $30 \mu \mathrm{M}$ ) inhibited plant growth by enhancing reactive oxygen species and lipid peroxidation in Arabidopsis (Ali et al., 2017) and soybean (Zhang et al., 2016). It was also reported that approximately 50-100 ppm BPA disrupted microtubule arrays, thereby inhibiting cell division in pea (Pisum sativum L.), the gymnosperm Abies cephalonica, Triticum turgidum (durum wheat) and Allium cepa (onion) (Adamakis et al., 2019, 2016, 2013). In addition, 5-10 ppm BPA inhibited pollen tube growth by decreasing the deposition of cell wall components through disrupting $\mathrm{Ca}^{2+}$ gradients and actin filaments in Picea meyeri (Chang et al., 2015). In mung bean (Vigna radiata), BPA treatment caused root and shoot growth retardation at the concentration of $750 \mathrm{ppm}$ and $1000 \mathrm{ppm}$ in soil, respectively (Kim et al., 2018a). Moreover, cucumber (Cucumis sativus L.) leaf infiltration with BPA inhibited photosynthesis rate and enhanced reactive oxygen species accumulation (Li et al., 2018a).

The plant hormone auxin has been implicated in various aspects of plant growth and responses to environmental stress, and its accumulation in different parts of the plant mainly relies on its synthesis, conjugation and degradation, and its distribution as affected by polar transport (Grieneisen et al., 2007; Li et al., 2011; Mano and Nemoto, 2012; Petrasek and Friml, 2009; Ruzicka et al., 2007; Wang et al., 2009). During the last decades, the involvement of auxin signaling and transport has been extensively explored in various aspects of root development, such as root cell division and elongation (Ding and Friml, 2010), directional growth of roots (Philosoph-Hadas et al., 2005; Rakusova et al., 2011), and root patterning (Friml et al., 2002; Petersson et al., 2009; Sabatini et al., 1999). The main components of polar auxin transport include the auxin influx carrier AUX1 (AUXIN RESISTANT 1) and the auxin efflux carriers PIN (PIN-FORMED) and ABCB (ATP-binding cassette family B) transporter family proteins (Balzan et al., 2014). In this regard, acropetal auxin transport is mediated mainly by PIN1/3/4/7 from the stele to the meristem, while basipetal transport through lateral root cap and 
epidermal cells is regulated by the function of PIN2 and AUX1 (Krecek et al., 2009).

Multiple tryptophan-dependent pathways have been proposed for auxin biosynthesis, including tryptamine (TAM), indole-3-acetaldoxime (IAOx), indole-3-acetamide (IAM), and indole-3-pyruvic acid (IPyA), in which different genes and enzymes such as AMI1 (AMIDASE-LIKE PROTEIN 1), AAO1 (ALDEHYDE OXIDASE 1), YUCCA (YUC), NIT (NITRILASE) and GH3 (PUTATIVE INDOLE-3-ACETIC ACID-AMIDO SYNTHETASE) regulate the synthesis of indole-3-acetic acid (IAA) as an auxin (Mashiguchi et al., 2011; Zhao, 2012).

The involvement of auxin biosynthesis and transport in root growth inhibition under different environmental stress conditions have been reported in several studies. For instance, root length inhibition in response to aluminum is attributed to the altered auxin synthesis via TAA1 (TRYPTOPHAN AMINOTRANSFERASE OF ARABIDOPSIS 1) and altered distribution through upregulation of $A U X 1$ and PIN2 expression (Sun et al., 2010; Yang et al., 2014). Manganese inhibited root elongation by decreasing auxin biosynthesis and auxin transport that was mediated by PIN4 and PIN7 (Zhao et al., 2017). Aluminum-treated barley (Hordeum vulgare) displayed root growth inhibition with enhanced expression of DR5 in the meristem, elongation zone, and stele in roots, suggesting that higher auxin may inhibit root growth, probably by decreasing root cell division and elongation (Bai et al., 2017). Copper treatment increased auxin activity ( $D R 5$ expression) in the meristem and elongation zones by reducing PIN1 expression, leading to reductions in meristem size, cell division activity, and elongation zone size in Arabidopsis (Yuan et al., 2013). Arabidopsis grown on low boron media showed a reduced root meristem size with higher auxin level (low DII-VENUS expression) in the stele, which was likely caused by reduced expression of PIN1 (Li et al., 2015a). Nitric oxide negatively regulated auxin transport via downregulation of PIN1, decreasing the primary root growth of Arabidopsis (Fernandez-Marcos et al., 2011). In another study, nitric oxide-mediated 
auxin accumulation and signaling were found to be responsible for $\mathrm{Cd}^{2+}$-induced root length reduction via reduction of PIN1/3/7 protein level and stabilization of AXR3 and IAA17 proteins (Yuan and Huang, 2016).

The connection between BPA and auxin in root growth inhibition was also suggested. In soybean, root growth and auxin (IAA) increased at $1.5 \mathrm{ppm}$ BPA, while both were reduced at over 3 ppm BPA (Li et al., 2018b; Wang et al., 2015). In addition, the expression level of auxin signaling gene $A C S 11$ encoding a 1-amino-cyclopropane-1-carboxylate synthase 11 was reduced by over $10 \mathrm{nM}$ BPA in Arabidopsis (Frejd et al., 2016).

Although negative effects of BPA on root growth have been reported in some studies, the molecular mechanisms underlying this inhibition remain poorly understood. Here we elucidated a mechanism that BPA inhibits primary root growth by inhibiting cell elongation and division through auxin accumulation/redistribution in Arabidopsis using gene expressions, mutants, reporter lines and a pharmacological approach because auxin is the most influential hormone in root growth. This study may contribute to understanding how BPA affects plant growth and development.

\section{Materials and methods}

\section{Plant materials and growth conditions}

All the experiments were performed in Arabidopsis thaliana ecotype Columbia (Col-0). Transgenic lines used in this study were as follows: DR5rev::GFP (ABRC, CS9361), pPIN1::PIN1-GFP (ABRC, CS23889), DII-VENUS (ABRC, CS799173), pPIN4::YFP (NASC, N2106114), $p U P B 1:: Y F P$ (NASC, N2106126), $p C Y C B 1 ; 1: \because G U S$ and $p D R 5:: G U S$ (Dr. Jun Lim, Konkuk Univ) (Kim et al., 2018b; Lee et al., 2012) , pPIN7::GUS, pPIN7::PIN7-GUS

(Dr. Eva Benková, Institute of Science and Technology, Austria) (Benkova et al., 2003), pAUX1::AUX1-YFP and pPIN2::PIN2-GFP (Dr. Klaus Palme, Albert-Ludwigs-University of 
Freiburg) (Swarup et al., 2008, 2001). Arabidopsis mutant lines including pin1 (SALK_047613), pin2 (SALK_122916C), pin3-4 (SALK_038609), pin4-3 (CS9368), pin7 (SALK_048791C), $\quad a b c b 1 \quad$ (SALK_046440), $\quad a b c b 4 \quad$ (SALK_072020), $a b c b 14-2$ (SALK_026876C), abcb15 (SALK_034562C), abcb19 (SALK_031406), and auxl (SALK_020355C) were obtained from the Arabidopsis Biological Resource Center (Ohio State University). All seeds were surface-sterilized and incubated for 3 days at $4{ }^{\circ} \mathrm{C}$ for vernalization. The seeds were sown in Petri dishes (90 mm diameter) containing a half-strength MS medium (Murashige and Skoog medium $\mathrm{pH}=5.7$ ). Then, the plates were placed vertically in a growth chamber under a 16-h light (cool white fluorescent light at $150 \mu \mathrm{mol} \mathrm{m} \mathrm{m}^{-2} \mathrm{~s}^{-1}$ )/8-h dark photoperiod and day/night temperatures of $23 / 21{ }^{\circ} \mathrm{C}$. BPA (Sigma-Aldrich, Korea, Cat\# 133027) was dissolved in DMSO to obtain a $100 \mathrm{mM}(22,829 \mathrm{mg} / \mathrm{L})$ stock solution and added to the media after autoclaving at the indicated concentrations. All the experiments were performed using 10-day-old seedlings unless otherwise indicated.

\section{Chemical treatments}

Stock solutions of 1-naphthylphthalamic acid (NPA) and 1-naphthoxyacetic acid (NOA) were prepared in DMSO, while that of potassium iodide were prepared in water and those of 1naphthaleneacetic acid (NAA) and indole-3-acetic acid (IAA) were prepared in $1 \mathrm{~N} \mathrm{NaOH}$, and they were added to the $1 / 2 \mathrm{MS}$ agar media after autoclaving to make the following concentrations: NPA (Sigma-Aldrich, Korea, Cat\# N12507) was prepared at $1 \mu \mathrm{M}$, NOA (Thermo Fisher Scientific, Korea, Cat\# L01036) at $1 \mu$ M, IAA (Sigma-Aldrich, Korea, Cat\# I2886) at 100 and $200 \mathrm{nM}$ and NAA (Sigma-Aldrich, Korea, Cat\# N0640) at 100 and $200 \mathrm{nM}$. The plants were treated with these chemicals for 10 days on agar media unless otherwise indicated. 


\section{Root examination and measurement}

The lengths of the primary root, root meristem, elongation zone and elongation zone cells and the number of root meristem cells were measured using 10-day-old Arabidopsis seedlings grown on 1/2 MS and 1/2 MS supplemented with the indicated concentrations of BPA. Except for the primary root length measurement, seedlings were incubated in $10 \mu \mathrm{g} \mathrm{ml}^{-1}$ propidium iodide for $10 \mathrm{~min}$ (Invitrogen, USA) to stain the cell wall. After washing (2-3 times) with distilled water to remove the excess dye, samples were examined with confocal laser scanning microscopy (Leica TCS SP5, Germany). The length and cell number of the root meristem were determined from the quiescent center to the starting point of the elongation zone. For elongation zone cell length, the length of each cell (from start point of elongation zone to the start point of differentiation zone) in the cortex layer was measured, and the average of all cells was indicated. To measure the newly grown root length, 7-day-old seedlings media were exposed to $10 \mathrm{ppm}$ BPA for $24 \mathrm{~h}$ and then transferred to the 1/2 MS agar media to grow for two more days. Consequently, the lengths of the newly grown roots for each treatment were measured. All the measurements were performed using ImageJ software (NIH, USA, http://rsb.info.nih.gov/ij). At least 30 plants were examined for each experiment, and the average of three independent biological experiments was calculated.

\section{RNA extraction and $q R T-P C R$ analyses}

RNA isolation, cDNA synthesis, and qRT-PCR were done as previously reported (Bahmani et al., 2017; Kim et al., 2019). Each qRT-PCR experiment was carried out at least three times with different cDNA sets obtained from three independent biological replicates. The sequence of the primers used for qRT-PCR is listed in Supporting Information Table 1.

\section{Confocal microscopy}

5-day-old seedlings of transgenic GFP and/or YFP reporter lines were examined using a 
confocal laser scanning microscopy (Leica TCS SP5, Germany). All seedlings were incubated in $10 \mu \mathrm{g} \mathrm{ml}^{-1}$ propidium iodide for $10 \mathrm{~min}$ (Invitrogen, USA), except for $p A U X 1:: A U X 1-Y F P$ and $p U P B 1: \because Y F P$, which are mounted in distilled water. The excitation and emission wavelengths were 488 and 505-520 $\mathrm{nm}$ for GFP, 514 and $530 \mathrm{~nm}$ for YFP, 538 and $617 \mathrm{~nm}$ for PI, respectively. Samples were observed at $20 \times$ magnification with an identical setting for each set of samples to obtain an accurate signal intensity comparison between images. The signal intensity was quantified using ImageJ software (NIH, USA, http://rsb.info.nih.gov/ij). For microscopy images, three independent experiments were performed in which at least 10 seedlings were photographed in each treatment, and a representative image is shown.

\section{B-Glucuronidase Assay}

Analysis of the $\beta$-glucuronidase activity in transgenic plants expressing a GUS reporter was carried out as previously described (Prasinos et al., 2005). In summary, 5-day-old seedlings were immersed in GUS assay solution (50 $\mathrm{mM} \mathrm{NaPO}_{4}$ buffer $\mathrm{pH}$ 6.8, $0.5 \mathrm{M}$ EDTA pH 8.0, 0.5 $\mathrm{mM}$ potassium ferrocyanide, $0.5 \mathrm{mM}$ potassium ferricyanide, $20 \%$ Triton X-100 and $2 \mathrm{mM} \mathrm{X-}$ gluc; 5-bromo-4-chloro-3-indolyl-D-glucuronidase) and incubated at $37^{\circ} \mathrm{C}$. The GUS staining duration varied for each marker line as follows: $3-8 \mathrm{~h}$ for $p D R 5: \because G U S, 2 \mathrm{~h}$ for $p C Y C B 1 ; 1: \because G U S$, 30 min for $p P I N 7:: P I N 7-G U S$ and $2 \mathrm{~h}$ for $p P I N 7:: G U S$. Images were captured with a microscope (Zeiss Axioplan2). This experiment was repeated three times, and 10 seedlings were examined for each line.

\section{Quantification of bisphenol A}

Wild-type (Col-0) Arabidopsis seedlings were grown vertically for 2 weeks on a 1/2 MS agar media supplemented with varying concentrations ( 0 to $10 \mathrm{ppm})$ of BPA. $1 \mathrm{~mL}$ of methanol (Sigma-Aldrich, Korea) was added to ground roots $(0.3 \mathrm{mg})$ and shoots $(0.6 \mathrm{mg})$, and extracted 
methanolic supernatants were analyzed. An Acquity UPLC-MS/MS system (Waters, Milford, MA, USA) was used with an electrospray ionization source. The column used for the separation was an Acquity UPLC BEH C18 $(1.7 \mu \mathrm{m}, 2.1 \times 100 \mathrm{~mm})$. The mobile phases consisted of distilled water (solvent A) and methanol (solvent B). The gradient elution was performed at a flow rate of $0.4 \mathrm{~mL} / \mathrm{min}$. The following gradient was employed: $0 \mathrm{~min}, 80: 20(\mathrm{~A}: \mathrm{B}) ; 4.5 \mathrm{~min}$, 35:65; $5.6 \mathrm{~min}, 100: 0 ; 7 \min 100: 0 ; 7.01 \mathrm{~min} 80: 20$; and 9:00 $\mathrm{min}, 80: 20$. The multiple reactions monitoring (MRM) was performed in the negative ion mode for mass detection. The target ions used for MRM were $m / z 227.1 \rightarrow 212.0$ for BPA and $m / z 241.3 \rightarrow 223.2$ for BPA-d16 (internal standard). The calibration curve was constructed over the concentration range of 10-500 ng/mL. The average of three independent biological experiments was calculated.

\section{Statistical analysis}

All data were subjected to an analysis of variance (ANOVA) using SAS software (version 9.1), and comparisons of the means were performed according to Tukey's test at $\mathrm{P} \leq 0.05$.

\section{Results}

\section{BPA reduces the length of the root elongation zone by repressing cell elongation}

Plants were germinated and grown for 14 days on agar media containing a range of concentrations of BPA. The 10 ppm BPA treatment reduced root length by $65 \%$ compared to treatments lacking BPA (Figure 1a and c), and there were no visible root hairs at 10 ppm BPA. Correspondingly, BPA accumulation in Arabidopsis increased dramatically at 10 ppm BPA, which explains why Arabidopsis growth was inhibited at $10 \mathrm{ppm}$ BPA (Figure 1b). To understand how the primary root growth was inhibited by BPA, the length of the elongation zone and the cell length were measured. As shown in Figures 1d, e and f, the elongation zone length and the cell length of elongation zone were reduced by approximately $20 \%$ in response 
to 10-day treatment of $10 \mathrm{ppm}$ BPA. To elucidate the mechanism for the reduction in the elongation zone cell length by BPA, the expressions of expansin genes involved in root cell elongation by cell wall loosening (Mcqueenmason and Cosgrove, 1994) were examined. As shown in Figure 1g, the expression of EXPA8 (Ma et al., 2013) and EXPA10 (Che et al., 2016; Kuluev et al., 2012), which are involved in root cell elongation by cell wall loosening, was inhibited by BPA treatment,. Among these expansin genes, the AtEXPA10 transcript level was greatly reduced, implying the importance of AtEXPA10 in root cell elongation. In support of this result, RNAseq data showed a 22-fold reduction of AtEXPA10 when plants were immersed in $1 \mathrm{ppm}$ BPA solution for $6 \mathrm{~h}$ (Table S2).

\section{BPA decreases the length of the root meristem by inhibiting cell division}

To examine another candidate for a mechanism by which BPA inhibits the primary root growth, the length and cell number of the meristem zone were measured. As shown in Figure 1f, 2a and b, the meristem length and meristem cell number were reduced by approximately $20 \%$ in response to a 10-day treatment of $10 \mathrm{ppm}$ BPA. Next, to examine a mechanism underlying the reduction in meristem cell number, the cell division activity of the meristem was examined using $C Y C B 1 ; 1:: G U S$-expressing Arabidopsis. As shown in Figures 2c, the reduced expression of $C Y C B 1 ; 1$ by BPA indicates decreased cell division activity. In addition, the transcript level and promoter activity of UPB1 (UPBEAT1), which promotes the transition from cellular proliferation to differentiation between the meristem zone and the elongation zone by regulating reactive oxygen species balance (Tsukagoshi et al., 2010), were enhanced by BPA (Figure 2d and e). This may result in the reduction in root meristem size, which is consistent with the phenotype of $U P B 1$-expressing Arabidopsis (Tsukagoshi et al., 2010).

BPA-induced auxin accumulation and redistribution in the root meristem and elongation 


\section{zone inhibits cell elongation and division}

To elucidate a mechanism for BPA-mediated inhibition of root growth, the auxin level was examined using the DR5 (auxin-responsive gene) expression in pDR5::GUS- (Ulmasov et al., 1997) and pDR5rev::GFP-expressing (Benkova et al., 2003) transgenic Arabidopsis. As shown in Figures 3a, DR5-GUS expression was enhanced at the meristem and stele by 1 ppm BPA and this expanded to the elongation zone at $10 \mathrm{ppm}$ BPA, indicating higher accumulation of auxin in these regions (meristem zone, elongation zone and stele) in response to BPA. DR5-GFP expression was also increased in the meristem zone and stele by 10 ppm BPA (Figure 3c). In addition, DR5-GUS expression was fully enhanced within $24 \mathrm{~h}$ by $10 \mathrm{ppm}$ BPA in the meristem zone, elongation zone and stele (Figure 3b). Furthermore, DII-VENUS, the auxin-signaling sensor (Brunoud et al., 2012), which is degraded by auxin, displayed a reduced expression in response to BPA, indicating higher accumulation of auxin by BPA (Figure 3d). These data suggest that in response to BPA, auxin was transported downward to the meristem zone via the stele and then was transported upward to the elongation zone; therefore, a higher level of auxin may repress cell division and cell elongation in the meristem zone and elongation zone, respectively. In addition, auxin over-accumulation may reduce root meristem enlargement ( $\mathrm{Li}$ et al., 2015b).

To examine whether the enhanced auxin actually inhibits cell elongation and division in roots, Col-0 Arabidopsis was germinated and grown for 10 days on 1/2 MS agar plates with and without $100 \mathrm{nM}$ and $200 \mathrm{nM}$ IAA and NAA. As shown in Figures 4a-d, primary root growth and expressions of $E X P A 8, E X P A 10$ and $C Y C B 1 ; 1$ were reduced by IAA and NAA, suggesting that BPA-induced auxin accumulation in the elongation zone and meristem zone inhibits root growth by reducing cell elongation and division.

\section{Auxin biosynthesis is enhanced in response to BPA}


To understand how the auxin level was increased in the meristem and stele, the expression levels of the auxin biosynthesis genes AtAAO1 (ALDEHYDE OXIDASE 1, AT5G20960), AtAMI1 (AMIDASE 1, AT1G08980), AtNIT1 (NITRILASE 1, AT3G44310), AtYUCCA1 (YUC1, AT4G32540), and AtYUCCA5 (YUC5, AT5G43890) were measured using qRT-PCR. As shown in Supporting Information Figure 1 (Figure S1), all genes involved in auxin biosynthesis except NIT1 displayed enhanced expressions in response to BPA, suggesting that BPA increased the auxin level in roots by enhancing the biosynthesis of auxin in Arabidopsis. Based on the enhanced expressions in $A A O 1$ and $A M I 1$ but not in NIT1 by BPA, it appears that BPA promotes the auxin synthetic pathway involving IPyA (indole-3-pyruvic acid) and IAM (indole-3-acetamide) rather than IAN (indole-3-acetonitrile).

\section{BPA modulates the auxin distribution in roots by regulating the expressions of auxin transporters}

To examine how auxin transporters participate in BPA-induced auxin distribution, the expression levels of the auxin transporter genes AtABCB1 (ATP-BINDING CASSETTE B1, AT2G36910), AtABCB4 (AT2G47000), AtABCB14 (AT1G28010), AtABCB15 (AT3G28345), AtABCB19 (AT3G28860), AtPIN1 (PIN-FORMED 1, AT1G73590), AtPIN2 (AT5G57090), AtPIN3 (AT1G70940), AtPIN4 (AT2G01420), AtPIN7 (AT1G23080) and AtAUX1 (AUXIN RESISTANT 1, AT2G38120) were examined using qRT-PCR. As shown in Supporting Information Figure 2 (Figure S2), the transcript levels of the auxin efflux transporters $A B C B S$ (ATP-BINDING CASSETTE B) and PINs (PIN-FORMED), except PIN3, were increased by BPA, while that of the auxin influx transporter $A U X 1$ was reduced in response to BPA. In addition, the protein expression levels of auxin transporters were examined (Figure 5). pPIN1::PIN1-GFP Arabidopsis showed that PIN1 protein was mainly expressed in the stele (Friml et al., 2002) and was enhanced by BPA (Figure 5a). While the transcript level of PIN2 
was enhanced by BPA (Figure S2), pPIN2::PIN2-GFP Arabidopsis displayed reduced expression of PIN2 protein (Figure 5b), suggesting that the protein level does not match the transcript content for PIN2. pPIN4::YFP-Arabidopsis showed that PIN4 was mainly expressed in the root tip (quiescent center and columella) and stele (Friml et al., 2002; Marques-Bueno et al., 2016), and the expression was enhanced but not expanded to other areas by BPA (Figure 5c). pPIN7::PIN7-GUS Arabidopsis indicated that PIN7 protein was expressed in the root tip (columella) and stele (Vieten et al., 2005) (Figure 5d). Interestingly, PIN7 protein was not increased by BPA, whereas the PIN7 transcript was enhanced by BPA (Figure 5d, e and S2), suggesting that PIN7 is not involved in auxin redistribution induced by BPA. In addition, pAUX1::AUX1::YFP-expressing Arabidopsis showed that BPA reduced the expression of the auxin influx transporter AUX1, which was localized in the epidermis, stele and tip (Figure 5f).

To confirm the involvement of auxin transporter-mediated auxin redistribution in BPAinduced root growth inhibition, root growth in response to BPA in auxin transporter mutants was examined. As shown in Figure 5g, most auxin transporter mutants examined, except pin 3 and $\operatorname{pin} 7$, displayed less reduction in root growth inhibition in response to BPA compared to the control Col-0. Since the PIN3 transcript level (Figure S2) and PIN7 protein level (Figure 5d) were not significantly increased by BPA, $\operatorname{pin} 3$ and $\operatorname{pin} 7$ did not show any difference from the control in root growth inhibition, suggesting that PIN3 and PIN7 are not involved in BPAinduced auxin redistribution. Therefore, auxin is redistributed in response to BPA via the auxin transporters PIN1, PIN2, PIN4, AUX1, and ABCBs in response to BPA.

To confirm the participation of auxin redistribution in BPA-induced root growth inhibition, NPA (auxin efflux inhibitor) and NOA (auxin influx inhibitor) were applied. As shown in Figure 6a, both NPA and NOA partially restored root growth inhibition incurred by BPA, indicating the partial engagement of auxin transporter-mediated auxin redistribution in BPA-inhibited root growth. In support of this, treatment with NPA or NOA decreased BPA- 
induced DR5-GUS expression/auxin accumulation in meristem zone, elongation zone and the stele (Figure 6b). Interestingly, NOA was more effective than NPA in reducing auxin accumulation. In addition, the NPA treatment partially rescued the BPA-inhibited expression of $C Y C B 1$; 1, which was not the case for NOA, suggesting the participation of auxin efflux but not influx in cell division inhibition induced by BPA (Figure 6c).

\section{Discussion}

In this study, for the first time, we have shown that BPA inhibits primary root growth by inhibiting cell division and elongation through auxin accumulation in the root meristem zone, transition zone, and elongation zone.

In response to $10 \mathrm{ppm} \mathrm{BPA,} \mathrm{the} \mathrm{length} \mathrm{of} \mathrm{the} \mathrm{meristem} \mathrm{zone} \mathrm{was} \mathrm{reduced} \mathrm{leading} \mathrm{to} \mathrm{a}$ decrease in the main root length. This result may be caused by BPA-induced accumulation of auxin in the meristem. However, it has been reported that auxin is positively involved in stem cell niche and cell division activity in the meristem (Sabatini et al., 1999; Takatsuka and Umeda, 2014). Therefore, the decreased auxin accumulation in root tips is responsible for the lower cell division activity in the root meristem, thereby inhibiting root growth (Fernandez-Marcos et al., 2011; Yuan and Huang, 2016; Zhao et al., 2017). By contrast, several reports showed that higher auxin accumulation is involved in inhibiting cell division, thereby in reducing the meristem size. Treatment with the cytokinin 6-benzyladenine reduced the meristem size and root length probably by increasing auxin level ( $D R 5$ expression) in the stele, meristem zone and elongation zone via decreasing PIN1, 2, and 3 expression and by enhancing the PIN7 level in Arabidopsis (Ruzicka et al., 2009). Alkaline stress decreased cell division activity by enhancing ethyleneand $A U X 1$-mediated auxin accumulation in the root meristem in Arabidopsis (Li et al., 2015b). Benzoic acid reduced the size of the meristem and elongation zone by ethylene-mediated auxin accumulation in root tips (meristem and elongation zone) via auxin biosynthesis, $A U X 1$ and 
PIN2 in Arabidopsis (Zhang et al., 2018a). Based on these findings, our results suggest that BPA reduces meristem size and thus root length by inhibiting cell division through accumulating auxin in the meristem. However, it is also possible that BPA directly inhibits cell division since BPA disrupts microtubule arrays in Pisum sativa, the gymnosperm Abies cephalonica, Triticum turgidum (durum wheat), and Allium cepa (onion) (Adamakis et al., 2019, 2016, 2013).

Furthermore, the reduced cell length of the elongation zone by BPA might be ascribed to decreased expression of EXPA8 and 10. Additionally, the BPA-induced accumulation of auxin in the transition zone and elongation zone (Figure 3a) may be responsible for the decreased cell elongation in the elongation zone, since auxin was negatively involved in cell elongation in the elongation zone when plants were challenged by benzoic acid (Zhang et al., 2018a), boron deficiency (Camacho-Cristobal et al., 2015) cell wall damage (Tsang et al., 2011), ethylene (Ruzicka et al., 2007; Swarup et al., 2007), and tungsten (Adamakis et al., 2014). Furthermore, the expression of EXPA8 and EXPA10 was reduced by IAA and NAA (Figure $4 \mathrm{~b}$ and c). Combining these results, it seems that the cell elongation repression by BPA is ascribed to the reduced expression of EXPA8 and 10 by higher accumulation of auxin in the elongation zone. However, in contrast to our results, several studies have shown a positive relationship between auxin and expansin expression. IAA-treated Arabidopsis seedlings showed higher expression levels of EXPA1, EXPA4, and EXLA3 (Nemhauser et al., 2006). Moreover, several expansin and related genes, including EXPA1, EXPA7, EXPA10, EXPA12, EXPA18, EXLA1, EXLA2, and EXLA3, were upregulated in response to picloram (4-amino-3,5,6trichloropicolinic acid; a synthetic auxin) in the elongating hypocotyls of Arabidopsis seedlings (Chapman et al., 2012). In CYP71Z2-overexpressing rice, which exhibited a lower level of IAA and higher resistance to bacterial blight, the expression levels of six expansin genes, including OsEXPA1, OsEXPA5, OsEXPA10, OsEXPB3, OsEXPB4 and OsEXPB7, were downregulated 
(Li et al., 2015c). In another study on rice, pathogen-induced IAA production positively regulates the transcript levels of expansin genes and enhanced cell wall flexibility (Cosgrove, 1993; Ding et al., 2008). In contrast, it was also reported that auxin is positively involved in cell elongation in the elongation zone; a lower level of auxin in the elongation zone due to aluminum-induced auxin accumulation in the transition zone is responsible for reduced cell elongation in Arabidopsis (Liu et al., 2016; Yang et al., 2014), and aluminum-treated maize displayed a decrease in auxin level in the transition zone and elongation zone, resulting in root growth inhibition (Zhang et al., 2018b), which supports the report of Kollmeier et al. (2000) in which IAA treatment to the elongation zone reduced root growth inhibition induced by alumium application to the transition zone.

The higher accumulation of auxin in the root meristem is attributed to the enhanced PIN1 and PIN4 levels and to reduced PIN2 and AUX1 expression (Figure 5). Since PIN1/4 are involved in the acropetal downward transport of auxin to the meristem via the stele (Blilou et al., 2005; Wabnik et al., 2011), the enhanced expression of PIN1/4 resulted in the higher level of auxin in the meristem. Consistent with this result, BPA increased the transcript levels of auxin efflux transporters $A B C B s$ (AtABCB1, AtABCB4, AtABCB14, AtABCB15 and AtABCB19), and PINs (AtPIN1, AtPIN2, AtPIN4 and AtPIN7), while that of the auxin influx transporter AUX1 was reduced in response to BPA (Figure S2).

PIN1 is positively involved in auxin accumulation in the root meristem/tip (FernandezMarcos et al., 2011; Ruzicka et al., 2007; Yuan and Huang, 2016; Yuan et al., 2013). In contrast, the auxin level increased at the stele with reduced PIN1 expression in response to benzyladenine (Ruzicka et al., 2009), copper (Yuan et al., 2013), and low boron (Li et al., 2015a). In addition, PIN3 (Yuan and Huang, 2016), PIN4 (Zhao et al., 2017) and PIN7 (Ruzicka et al., 2009; Yuan and Huang, 2016; Zhao et al., 2017) are engaged in auxin accumulation in roots. Interestingly, PIN2 and $A U X 1$, which participate in the basipetal shootward transport of auxin, are positively 
involved in auxin accumulation in the root meristem zone and elongation zone (CamachoCristobal et al., 2015; Ruzicka et al., 2007; Swarup et al., 2007; Zhang et al., 2018a). Therefore, the BPA-inhibited expression of PIN2 and $A U X 1$ (Figure 5) suggests that sufficient auxin is transported to the elongation zone, even with lower levels of PIN2 and AUX1. Similar results were also reported in root growth inhibition by boron deficiency (Camacho-Cristobal et al., 2015).

In addition, the enhanced expression of $A B C B 1 / 4 / 19$ by BPA (Figure S2) likely enables higher amounts of auxin to translocate upward from the root tip to the elongation zone. Basipetal auxin transport in the root tip of Arabidopsis is mediated by the concerted function of PIN2 (Friml et al., 2003; Muller et al., 1998), $A B C B 1$ (Geisler et al., 2005), $A B C B 4$ (Terasaka et al., 2005; Wu et al., 2007), and $A U X 1$ (Swarup et al., 2001) towards the root elongation zone. The $a b c b 1$ and $a b c b 4$ mutants exhibited reduced basipetal auxin transport (Geisler et al., 2005; Lewis et al., 2007). However, the functional redundancy of $A t A B C B 1$ and $A B C B 19$ cannot be excluded (Bouchard et al., 2006; Geisler et al., 2003).

In conclusion, BPA inhibits primary root growth by repressing cell division in the meristem zone and cell elongation in the elongation zone through auxin accumulation/redistribution in the meristem zone and elongation zone in Arabidopsis.

\section{Acknowledgments}

This work was supported by the Civil Research Projects for Solving Social Problems through the National Research Foundation of Korea (NRF) funded by the Ministry of Science, ICT \& Future Planning [NRF-2015M3C8A6A06014500], and by the Korea Institute of Planning and Evaluation for Technology in Food, Agriculture, Forestry and Fisheries (IPET) through the Agri-Bio industry Technology Development Program, funded by Ministry of Agriculture, Food and Rural Affairs (MAFRA) (IPET 316087-4), Korea. We thank Prof. Jun Lim (Konkuk 
University, Korea) for providing the $p C Y C B 1 ; 1:: G U S$ and $p D R 5:: G U S$ lines, Prof. Eva Benková (Institute of Science and Technology, Austria) for the $p P I N 4:: G U S, p P I N 7:: G U S$ and pPIN7::PIN7-GUS lines, and Prof. Klaus Palme (Albert-Ludwigs-University of Freiburg, Germany) for the $p A U X 1:: A U X 1-Y F P$ and $p P I N 2: \because P I N 2-G F P$ lines. The authors declare no competing financial interests.

\section{References}

Adamakis, I.D.S., Panteris, E., Cherianidou, A., Eleftheriou, E.P., 2013. Effects of bisphenol A on the microtubule arrays in root meristematic cells of Pisum sativum L. Mutat. Res/Genet. Toxicol. Environ. Mutagen. 750, 111-120. https://doi.org/10.1016/j.mrgentox.2012.10.012

Adamakis, I.D.S., Panteris, E., Eleftheriou, E.P., 2019. Tubulin acetylation mediates bisphenol A effects on the microtubule arrays of Allium cepa and Triticum turgidum. Biomolecules 9. https://doi.org/Artn 18510.3390/Biom9050185

Adamakis, I.D.S., Panteris, E., Eleftheriou, E.P., 2016. Bisphenol A disrupts microtubules and induces multipolar spindles in dividing root tip cells of the gymnosperm Abies cephalonica. Chemosphere 149, $202-210$. https://doi.org/10.1016/j.chemosphere.2016.01.082

Adamakis, I.D.S., Panteris, E., Eleftheriou, E.P., 2014. Tungsten disrupts root growth in Arabidopsis thaliana by PIN targeting. J. Plant Physiol. 171, 1174-1187. https://doi.org/10.1016/j.jplph.2014.04.010

Ali, I., Jan, M., Wakeel, A., Azizullah, A., Liu, B.H., Islam, F., Ali, A., Daud, M.K., Liu, Y.H., Gan, Y.B., 2017. Biochemical responses and ultrastructural changes in ethylene insensitive mutants of Arabidopsis thialiana subjected to bisphenol A exposure. Ecotoxicol. Environ. Saf. 144, 62-71. https://doi.org/10.1016/j.ecoenv.2017.06.015

Bahmani, R., Kim, D.G., Lee, B.D., Hwang, S., 2017. Over-expression of tobacco UBC1 encoding a ubiquitinconjugating enzyme increases cadmium tolerance by activating the 20S/26S proteasome and by decreasing $\mathrm{Cd}$ accumulation and oxidative stress in tobacco (Nicotiana tabacum). Plant Mol. Biol. 94. https://doi.org/10.1007/s11103-017-0616-6

Bai, B., Bian, H.W., Zeng, Z.H., Hou, N., Shi, B., Wang, J.H., Zhu, M.Y., Han, N., 2017. miR393-mediated auxin signaling regulation is involved in root elongation inhibition in response to toxic aluminum stress in barley. Plant Cell Physiol. 58, 426-439. https://doi.org/10.1093/pcp/pcw211

Balzan, S., Johal, G.S., Carraro, N., 2014. The role of auxin transporters in monocots development. Front. Plant Sci. 5. https://doi.org/Artn 39310.3389/Fpls.2014.00393

Benkova, E., Michniewicz, M., Sauer, M., Teichmann, T., Seifertova, D., Jurgens, G., Friml, J., 2003. Local, effluxdependent auxin gradients as a common module for plant organ formation. Cell 115, 591-602. https://doi.org/Doi 10.1016/S0092-8674(03)00924-3

Blilou, I., Xu, J., Wildwater, M., Willemsen, V., Paponov, I., Friml, J., Heidstra, R., Aida, M., Palme, K., Scheres, B., 2005. The PIN auxin efflux facilitator network controls growth and patterning in Arabidopsis roots. Nature 433, 39-44. https://doi.org/10.1038/nature03184

Bouchard, R., Bailly, A., Blakeslee, J.J., Oehring, S.C., Vincenzetti, V., Lee, O.R., Paponov, I., Palme, K., Mancuso, S., Murphy, A.S., Schulz, B., Geisler, M., 2006. Immunophilin-like TWISTED DWARF1 modulates auxin efflux activities of Arabidopsis P-glycoproteins. J. Biol. Chem. 281, 30603-30612. https://doi.org/10.1074/jbc.M604604200

Brunoud, G., Wells, D.M., Oliva, M., Larrieu, A., Mirabet, V., Burrow, A.H., Beeckman, T., Kepinski, S., Traas, J., Bennett, M.J., Vernoux, T., 2012. A novel sensor to map auxin response and distribution at high spatiotemporal resolution. Nature 482, 103-U132. https://doi.org/10.1038/nature10791

Camacho-Cristobal, J.J., Martin-Rejano, E.M., Herrera-Rodriguez, M.B., Navarro-Gochicoa, M.T., Rexach, J., Gonzalez-Fontes, A., 2015. Boron deficiency inhibits root cell elongation via an ethylene/auxin/ROSdependent pathway in Arabidopsis seedlings. J. Exp. Bot. 66, 3831-3840. https://doi.org/10.1093/jxb/erv186

Canesi, L., Fabbri, E., 2015. Environmental effects of BPA: focus on aquatic species. Dose-Response 13. https://doi.org/10.1177/1559325815598304 
Chang, T.J., Fan, C.Y., Man, Y., Zhou, J.H., Jing, Y.P., 2015. Bisphenol A affects germination and tube growth in Picea meyeri pollen through modulating $\mathrm{Ca}^{2+}$ flux and disturbing actin-dependent vesicular trafficking during cell wall construction. Plant Physiol. Biochem. 94, 216-224. https://doi.org/10.1016/j.plaphy.2015.06.010

Chapman, E.J., Greenham, K., Castillejo, C., Sartor, R., Bialy, A., Sun, T.P., Estelle, M., 2012. Hypocotyl transcriptome reveals auxin regulation of growth-promoting genes through GA-dependent and independent pathways. PLoS One 7. https://doi.org/ARTN e3621010.1371/journal.pone.0036210

Che, J., Yamaji, N., Shen, R.F., Ma, J.F., 2016. An Al-inducible expansin gene, OsEXPA10 is involved in root cell elongation of rice. Plant J. 88, 132-142. https://doi.org/10.1111/tpj.13237

Cooper, J.E., Kendig, E.L., Belcher, S.M., 2011. Assessment of bisphenol A released from reusable plastic, aluminium and stainless steel water bottles. Chemosphere 85, 943-947. https://doi.org/10.1016/j.chemosphere.2011.06.060

Cosgrove, D.J., 1993. Wall extensibility: its nature, measurement and relationship to plant cell growth. New Phytol. 124, 1-23. https://doi.org/DOI 10.1111/j.1469-8137.1993.tb03795.x

Ding, X.H., Cao, Y.L., Huang, L.L., Zhao, J., Xu, C.G., Li, X.H., Wang, S.P., 2008. Activation of the indole-3acetic acid-amido synthetase GH3-8 suppresses expansin expression and promotes salicylate- and jasmonate-independent basal immunity in rice. Plant Cell 20, 228-240. https://doi.org/10.1105/tpc.107.055657

Ding, Z.J., Friml, J., 2010. Auxin regulates distal stem cell differentiation in Arabidopsis roots. Proc. Natl. Acad. Sci. U. S. A. 107, 12046-12051. https://doi.org/10.1073/pnas.1000672107

Fernandez-Marcos, M., Sanz, L., Lewis, D.R., Muday, G.K., Lorenzo, O., 2011. Nitric oxide causes root apical meristem defects and growth inhibition while reducing PIN-FORMED 1 (PIN1)-dependent acropetal auxin transport. Proc. Natl. Acad. Sci. U. S. A. 108, 18506-18511. https://doi.org/10.1073/pnas.1108644108

Ferrara, G., Loffredo, E., Senesi, N., 2006. Phytotoxic, clastogenic and bioaccumulation effects of the environmental endocrine disruptor bisphenol A in various crops grown hydroponically. Planta 223, 910-916. https://doi.org/10.1007/s00425-005-0147-2

Flint, S., Markle, T., Thompson, S., Wallace, E., 2012. Bisphenol A exposure, effects, and policy: A wildlife perspective. J. Environ. Manage. 104, 19-34. https://doi.org/10.1016/j.jenvman.2012.03.021

Frejd, D., Dunaway, K., Hill, J., Van Maanen, J., Carlson, C., 2016. The genomic and morphological effects of bisphenol A on Arabidopsis thaliana. PLoS One 11, 1-10. https://doi.org/10.1371/journal.pone.0163028

Friml, J., Benkova, E., Blilou, I., Wisniewska, J., Hamann, T., Ljung, K., Woody, S., Sandberg, G., Scheres, B., Jurgens, G., Palme, K., 2002. AtPIN4 mediates sink-driven auxin gradients and root patterning in Arabidopsis. Cell 108, 661-673. https://doi.org/Doi 10.1016/S0092-8674(02)00656-6

Friml, J., Benkova, E., Mayer, U., Palme, K., Muster, G., 2003. Automated whole mount localisation techniques for plant seedlings. Plant J. 34, 115-124. https://doi.org/DOI 10.1046/j.1365-313X.2003.01705.X

Geisler, M., Blakeslee, J.J., Bouchard, R., Lee, O.R., Vincenzetti, V., Bandyopadhyay, A., Titapiwatanakun, B., Peer, W.A., Bailly, A., Richards, E.L., Ejenda, K.F.K., Smith, A.P., Baroux, C., Grossniklaus, U., Muller, A., Hrycyna, C.A., Dudler, R., Murphy, A.S., Martinoia, E., 2005. Cellular efflux of auxin catalyzed by the Arabidopsis MDR/PGP transporter AtPGP1. Plant J. 44, 179-194. https://doi.org/10.1111/j.1365313X.2005.02519.X

Geisler, M., Kolukisaoglu, H.U., Bouchard, R., Billion, K., Berger, J., Saal, B., Frangne, N., Koncz-Kalman, Z., Koncz, C., Dudler, R., Blakeslee, J.J., Murphy, A.S., Martinoia, E., Schulz, B., 2003. TWISTED DWARF1, a unique plasma membrane-anchored immunophilin-like protein, interacts with Arabidopsis multidrug resistance-like transporters AtPGP1 and AtPGP19. Mol. Biol. Cell 14, 4238-4249. https://doi.org/DOI 10.1091/mbc.E02-10-0698

Goodson, A., Summerfield, W., Cooper, I., 2002. Survey of bisphenol A and bisphenol F in canned foods. Food Addit. Contam. 19, 796-802. https://doi.org/10.1080/02652030210146837

Grieneisen, V.A., Xu, J., Maree, A.F.M., Hogeweg, P., Scheres, B., 2007. Auxin transport is sufficient to generate a maximum and gradient guiding root growth. Nature 449, 1008-1013. https://doi.org/10.1038/nature06215

Hunt, P.A., Susiarjo, M., Rubio, C., Hassold, T.J., 2009. The bisphenol A experience: A primer for the analysis of environmental effects on mammalian reproduction. Biol. Reprod. 81, 807-813. https://doi.org/10.1095/biolreprod.109.077008

Kim, D., Bahmani, R., Ko, J.H., Hwang, S., 2019. Development of bisphenol A (BPA)-sensing indicator Arabidopsis thaliana which synthesizes anthocyanin in response to BPA in leaves. Ecotoxicol. Environ. Saf. 170, 627-634. https://doi.org/10.1016/j.ecoenv.2018.12.029

Kim, D., Kwak, J.I., An, Y.J., 2018a. Effects of bisphenol A in soil on growth, photosynthesis activity, and genistein levels in crop plants (Vigna radiata). Chemosphere 209, 875-882. https://doi.org/10.1016/j.chemosphere.2018.06.146

Kim, G., Jang, S., Yoon, E.K., Lee, S.A., Dhar, S., Kim, J., Lee, M.M., Lim, J., 2018b. Involvement of pyridoxine/pyridoxamine $5^{\prime}$-phosphate oxidase (PDX3) in ethylene-induced auxin biosynthesis in the 
Arabidopsis root. Mol. Cells 41, 1033-1044. https://doi.org/10.14348/molcells.2018.0363

Kollmeier, M., Felle, H.H., Horst, W.J., 2000. Genotypical differences in aluminum resistance of maize are expressed in the distal part of the transition zone. Is reduced basipetal auxin flow involved in inhibition of root elongation by aluminum? Plant Physiol. 122, 945-956. https://doi.org/Doi 10.1104/Pp.122.3.945

Krecek, P., Skupa, P., Libus, J., Naramoto, S., Tejos, R., Friml, J., Zazimalova, E., 2009. The PIN-FORMED (PIN) protein family of auxin transporters. Genome Biol. 10. https://doi.org/Artn 24910.1186/Gb-2009-10-12-249

Kuluev, B.R., Knyazev, A.B., Lebedev, Y.P., Chemeris, A. V, 2012. Morphological and physiological characteristics of transgenic tobacco plants expressing expansin genes: AtEXP10 from Arabidopsis and PnEXPA1 from poplar. Russ. J. Plant Physiol. 59, 97-104. https://doi.org/10.1134/S1021443712010128

Lee, S.A., Yoon, E.K., Heo, J.O., Lee, M.H., Hwang, I., Cheong, H., Lee, W.S., Hwang, Y.S., Lim, J., 2012. Analysis of Arabidopsis glucose insensitive growth mutants reveals the involvement of the plastidial copper transporter PAA1 in glucose-induced intracellular signaling. Plant Physiol. 159, 1001-1012. https://doi.org/10.1104/pp.111.191726

Lewis, D.R., Miller, N.D., Splitt, B.L., Wu, G.S., Spalding, E.P., 2007. Separating the roles of acropetal and basipetal auxin transport on gravitropism with mutations in two Arabidopsis multidrug resistance-like ABC transporter genes. Plant Cell 19, 1838-1850. https://doi.org/10.1105/tpc.107.051599

Li, Y.T., Liang, Y., Li, Y.N., Che, X.K., Zhao, S.J., Zhang, Z.S., Gao, H.Y., 2018a. Mechanisms by which bisphenol A affect the photosynthetic apparatus in cucumber (Cucumis sativus L.) leaves. Sci. Rep. 8, 1-9. https://doi.org/10.1038/s41598-018-22486-4

Li, X.Y., Wang, L.H., Shen, F., Zhou, Q., Huang, X.H., 2018b. Impacts of exogenous pollutant bisphenol A on characteristics of soybeans. Ecotoxicol. Environ. Saf. 157, 463-471. https://doi.org/10.1016/j.ecoenv.2018.04.013

Li, K., Kamiya, T., Fujiwara, T., 2015a. Differential roles of PIN1 and PIN2 in root meristem maintenance under low-B conditions in Arabidopsis thaliana. Plant Cell Physiol. 56, 1205-1214. https://doi.org/10.1093/pcp/pcv047

Li, J., Xu, H.H., Liu, W.C., Zhang, X.W., Lu, Y.T., 2015b. Ethylene inhibits root elongation during alkaline stress through AUXIN1 and associated changes in auxin accumulation. Plant Physiol. 168, 1777-U1154. https://doi.org/10.1104/pp.15.00523

Li, W.Q., Wang, F.Q., Wang, J., Fan, F.J., Zhu, J.Y., Yang, J., Liu, F.Q., Zhong, W.G., 2015c. Overexpressing CYP71Z2 enhances resistance to bacterial blight by suppressing auxin biosynthesis in rice. PLoS One 10. https://doi.org/ARTN e011986710.1371/journal.pone.0119867

Li, B.H., Li, Q., Su, Y.H., Chen, H., Xiong, L.M., Mi, G.H., Kronzucker, H.J., Shi, W.M., 2011. Shoot-supplied ammonium targets the root auxin influx carrier AUX1 and inhibits lateral root emergence in Arabidopsis. Plant Cell Environ. 34, 933-946. https://doi.org/10.1111/j.1365-3040.2011.02295.x

Liu, G.C., Gao, S., Tian, H.Y., Wu, W.W., Robert, H.S., Ding, Z.J., 2016. Local transcriptional control of YUCCA regulates auxin promoted root-growth inhibition in response to aluminium stress in Arabidopsis. Plos Genet. 12. https://doi.org/ARTN e100636010.1371/journal.pgen.1006360

Ma, N.N., Wang, Y., Qiu, S.C., Kang, Z.H., Che, S.G., Wang, G.X., Huang, J.L., 2013. Overexpression of OsEXPA8, a root-specific gene, improves rice growth and root system architecture by facilitating cell extension. PLoS One 8. https://doi.org/ARTN e7599710.1371/journal.pone.0075997

Mano, Y., Nemoto, K., 2012. The pathway of auxin biosynthesis in plants. J. Exp. Bot. 63, $2853-2872$. https://doi.org/10.1093/jxb/ers091

Marques-Bueno, M.M., Morao, A.K., Cayrel, A., Platre, M.P., Barberon, M., Caillieux, E., Colot, V., Jaillais, Y., Roudier, F., Vert, G., 2016. A versatile multisite gateway-compatible promoter and transgenic line collection for cell type-specific functional genomics in Arabidopsis. Plant J. 85, 320-333. https://doi.org/10.1111/tpj.13099

Mashiguchi, K., Tanaka, K., Sakai, T., Sugawara, S., Kawaide, H., Natsume, M., Hanada, A., Yaeno, T., Shirasu, K., Yao, H., McSteen, P., Zhao, Y.D., Hayashi, K., Kamiya, Y., Kasahara, H., 2011. The main auxin biosynthesis pathway in Arabidopsis. Proc. Natl. Acad. Sci. U. S. A. 108, 18512-18517. https://doi.org/10.1073/pnas.1108434108

Mcqueenmason, S., Cosgrove, D.J., 1994. Disruption of hydrogen-bonding between plant-cell wall polymers by proteins that induce wall extension. Proc. Natl. Acad. Sci. U. S. A. 91, 6574-6578. https://doi.org/DOI 10.1073/pnas.91.14.6574

Meesters, R.J.W., Schroder, H.F., 2002. Simultaneous determination of 4-nonylphenol and bisphenol A in sewage sludge. Anal. Chem. 74, 3566-3574. https://doi.org/10.1021/ac011258q

Mihaich, E.M., Friederich, U., Caspers, N., Hall, A.T., Klecka, G.M., Dimond, S.S., Staples, C.A., Ortego, L.S., Hentges, S.G., 2009. Acute and chronic toxicity testing of bisphenol A with aquatic invertebrates and plants. Ecotoxicol. Environ. Saf. 72, 1392-1399. https://doi.org/10.1016/j.ecoenv.2009.02.005

Muller, A., Guan, C.H., Galweiler, L., Tanzler, P., Huijser, P., Marchant, A., Parry, G., Bennett, M., Wisman, E., Palme, K., 1998. AtPIN2 defines a locus of Arabidopsis for root gravitropism control. Embo J. 17, 6903- 
6911. https://doi.org/DOI 10.1093/emboj/17.23.6903

Nemhauser, J.L., Hong, F.X., Chory, J., 2006. Different plant hormones regulate similar processes through largely nonoverlapping transcriptional responses. Cell 126, 467-475. https://doi.org/10.1016/j.cell.2006.05.050

Pan, W.J., Xiong, C., Wu, Q.P., Liu, J.X., Liao, H.M., Chen, W., Liu, Y.S., Zheng, L., 2013. Effect of BPA on the germination, root development, seedling growth and leaf differentiation under different light conditions in Arabidopsis thaliana. Chemosphere 93, 2585-2592. https://doi.org/10.1016/j.chemosphere.2013.09.081

Petersson, S. V, Johansson, A.I., Kowalczyk, M., Makoveychuk, A., Wang, J.Y., Moritz, T., Grebe, M., Benfey, P.N., Sandberg, G., Ljung, K., 2009. An auxin gradient and maximum in the Arabidopsis root apex shown by high-resolution cell-specific analysis of IAA distribution and synthesis. Plant Cell 21, 1659-1668. https://doi.org/10.1105/tpc.109.066480

Petrasek, J., Friml, J., 2009. Auxin transport routes in plant development. Development 136, $2675-2688$. https://doi.org/10.1242/dev.030353

Philosoph-Hadas, S., Friedman, H., Meir, S., 2005. Gravitropic bending and plant hormones. Plant Horm. 72, 3178. https://doi.org/10.1016/S0083-6729(05)72002-1

Prasinos, C., Krampis, K., Samakovli, D., Hatzopoulos, P., 2005. Tight regulation of expression of two Arabidopsis cytosolic Hsp90 genes during embryo development. J. Exp. Bot. 56, 633-644. https://doi.org/10.1093/jxb/eri035

Qiu, Z.Y., Wang, L.H., Zhou, Q., 2013. Effects of bisphenol A on growth, photosynthesis and chlorophyll fluorescence in above-ground organs of soybean seedlings. Chemosphere 90, 1274-1280. https://doi.org/10.1016/j.chemosPhere.2012.09.085

Rakusova, H., Gallego-Bartolome, J., Vanstraelen, M., Robert, H.S., Alabadi, D., Blazquez, M.A., Benkova, E., Friml, J., 2011. Polarization of PIN3-dependent auxin transport for hypocotyl gravitropic response in Arabidopsis thaliana. Plant J. 67, 817-826. https://doi.org/10.1111/j.1365-313X.2011.04636.X

Ruzicka, K., Simaskova, M., Duclercq, J., Petrasek, J., Zazimalova, E., Simon, S., Friml, J., Van Montagu, M.C.E., Benkova, E., 2009. Cytokinin regulates root meristem activity via modulation of the polar auxin transport. Proc. Natl. Acad. Sci. U. S. A. 106, 4284-4289. https://doi.org/10.1073/pnas.0900060106

Ruzicka, K., Ljung, K., Vanneste, S., Podhorska, R., Beeckman, T., Friml, J., Benkova, E., 2007. Ethylene regulates root growth through effects on auxin biosynthesis and transport-dependent auxin distribution. Plant Cell 19, 2197-2212. https://doi.org/10.1105/tpc.107.052126

Sabatini, S., Beis, D., Wolkenfelt, H., Murfett, J., Guilfoyle, T., Malamy, J., Benfey, P., Leyser, O., Bechtold, N., Weisbeek, P., Scheres, B., 1999. An auxin-dependent distal organizer of pattern and polarity in the Arabidopsis root. Cell 99, 463-472. https://doi.org/Doi 10.1016/S0092-8674(00)81535-4

Sun, P., Tian, Q.Y., Chen, J., Zhang, W.H., 2010. Aluminium-induced inhibition of root elongation in Arabidopsis is mediated by ethylene and auxin. J. Exp. Bot. 61, 347-356. https://doi.org/10.1093/jxb/erp306

Swarup, K., Benkova, E., Swarup, R., Casimiro, I., Peret, B., Yang, Y., Parry, G., Nielsen, E., De Smet, I., Vanneste, S., Levesque, M.P., Carrier, D., James, N., Calvo, V., Ljung, K., Kramer, E., Roberts, R., Graham, N., Marillonnet, S., Patel, K., Jones, J.D.G., Taylor, C.G., Schachtman, D.P., May, S., Sandberg, G., Benfey, P., Friml, J., Kerr, I., Beeckman, T., Laplaze, L., Bennett, M.J., 2008. The auxin influx carrier LAX3 promotes lateral root emergence. Nat. Cell Biol. 10, 946-954. https://doi.org/10.1038/ncb1754

Swarup, R., Perry, P., Hagenbeek, D., Van Der Straeten, D., Beemster, G.T.S., Sandberg, G., Bhalerao, R., Ljung, K., Bennett, M.J., 2007. Ethylene upregulates auxin biosynthesis in Arabidopsis seedlings to enhance inhibition of root cell elongation. Plant Cell 19, 2186-2196. https://doi.org/10.1105/tpc.107.052100

Swarup, R., Friml, J., Marchant, A., Ljung, K., Sandberg, G., Palme, K., Bennett, M., 2001. Localization of the auxin permease AUX1 suggests two functionally distinct hormone transport pathways operate in the Arabidopsis root apex. Genes Dev. 15, 2648-2653. https://doi.org/Doi 10.1101/Gad.210501

Takatsuka, H., Umeda, M., 2014. Hormonal control of cell division and elongation along differentiation trajectories in roots. J. Exp. Bot. 65, 2633-2643. https://doi.org/10.1093/jxb/ert485

Terasaka, K., Blakeslee, J.J., Titapiwatanakun, B., Peer, W.A., Bandyopadhyay, A., Makam, S.N., Lee, O.R., Richards, E.L., Murphy, A.S., Sato, F., Yazaki, K., 2005. PGP4, an ATP binding cassette P-glycoprotein, catalyzes auxin transport in Arabidopsis thaliana roots. Plant Cell 17, 2922-2939. https://doi.org/10.1105/tpc.105.035816

Terouchi, N., Takano, K., Nakamura, Y., Enomoto, K., Hosoya, N., Nishinari, N., 2004. Bisphenol A stimulates growth and shoot differentiation in plants. Plant Biotechnol. 21, 307-308. https://doi.org/10.5511/plantbiotechnology.21.307

Tsang, D.L., Edmond, C., Harrington, J.L., Nuhse, T.S., 2011. Cell wall integrity controls root elongation via a general 1-aminocyclopropane-1-carboxylic acid-dependent, ethylene-independent pathway. Plant Physiol. 156, 596-604. https://doi.org/10.1104/pp.111.175372

Tsukagoshi, H., Busch, W., Benfey, P.N., 2010. Transcriptional regulation of ROS controls transition from proliferation to differentiation in the root. Cell 143, 606-616. https://doi.org/10.1016/j.cell.2010.10.020

Ulmasov, T., Murfett, J., Hagen, G., Guilfoyle, T.J., 1997. Aux/IAA proteins repress expression of reporter genes 
containing natural and highly active synthetic auxin response elements. Plant Cell 9, 1963-1971. https://doi.org/DOI 10.1105/tpc.9.11.1963

Vieten, A., Vanneste, S., Wisniewska, J., Benkova, E., Benjamins, R., Beeckman, T., Luschnig, C., Friml, J., 2005. Functional redundancy of PIN proteins is accompanied by auxin-dependent cross-regulation of PIN expression. Development 132, 4521-4531. https://doi.org/10.1242/dev.02027

Wabnik, K., Govaerts, W., Friml, J., Kleine-Vehn, J., 2011. Feedback models for polarized auxin transport: an emerging trend. Mol. Biosyst. 7, 2352-2359. https://doi.org/10.1039/c1mb05109a

Wang, S., Wang, L., Hua, W., Zhou, M., Wang, Q., Zhou, Q., Huang, X., 2015. Effects of bisphenol A, an environmental endocrine disruptor, on the endogenous hormones of plants. Environ. Sci. Pollut. Res. 22, 17653-17662. https://doi.org/10.1007/s11356-015-4972-y

Wang, Y.N., Li, K.X., Li, X., 2009. Auxin redistribution modulates plastic development of root system architecture under salt stress in Arabidopsis thaliana. J. Plant Physiol. 166, 1637-1645. https://doi.org/10.1016/j.jplph.2009.04.009

Wee, S.Y., Aris, A.Z., 2017. Endocrine disrupting compounds in drinking water supply system and human health risk implication. Environ. Int. 106, 207-233. https://doi.org/10.1016/j.envint.2017.05.004

Wu, G., Lewis, D.R., Spalding, E.P., 2007. Mutations in Arabidopsis multidrug resistance-like ABC transporters separate the roles of acropetal and basipetal auxin transport in lateral root development. Plant Cell 19, 18261837. https://doi.org/10.1105/tpc.106.048777

Yang, Z.B., Geng, X.Y., He, C.M., Zhang, F., Wang, R., Horst, W.J., Ding, Z.J., 2014. TAA1-regulated local auxin biosynthesis in the root-apex transition zone mediates the aluminum-induced inhibition of root growth in Arabidopsis. Plant Cell 26, 2889-2904. https://doi.org/10.1105/tpc.114.127993

Yuan, H.M., Huang, X., 2016. Inhibition of root meristem growth by cadmium involves nitric oxide-mediated repression of auxin accumulation and signalling in Arabidopsis. Plant Cell Environ. 39, 120-135. https://doi.org/10.1111/pce.12597

Yuan, H.M., Xu, H.H., Liu, W.C., Lu, Y.T., 2013. Copper regulates primary root elongation through PIN1-mediated auxin redistribution. Plant Cell Physiol. 54, 766-778. https://doi.org/10.1093/pcp/pct030

Zhang, W., Lu, L.Y., Hu, L.Y., Cao, W., Sun, K., Sun, Q.B., Siddikee, A., Shi, R.H., Dai, C.C., 2018a. Evidence for the involvement of auxin, ethylene and ROS signaling during primary root inhibition of Arabidopsis by the allelochemical benzoic acid. Plant Cell Physiol. 59, 1889-1904. https://doi.org/10.1093/pcp/pcy107

Zhang, M., Lu, X., Li, C., Zhang, B., Zhang, C., Zhang, X.S., Ding, Z., 2018b. Auxin efflux carrier ZmPGP1 mediates root growth inhibition under aluminum stress. Plant Physiol. 177, 819-832. https://doi.org/10.1104/pp.17.01379

Zhang, J., Li, X., Zhou, L., Wang, L., Zhou, Q., Huang, X., 2016. Analysis of effects of a new environmental pollutant, bisphenol A, on antioxidant systems in soybean roots at different growth stages. Sci. Rep. 6, 1-10. https://doi.org/10.1038/srep23782

Zhao, J.J., Wang, W.Y., Zhou, H.K., Wang, R.L., Zhang, P., Wang, H.C., Pan, X.L., Xu, J., 2017. Manganese toxicity inhibited root growth by disrupting auxin biosynthesis and transport in Arabidopsis. Front. Plant Sci. 8, 1-8. https://doi.org/Artn 27210.3389/Fpls.2017.00272

Zhao, Y.D., 2012. Auxin Biosynthesis: A simple two-step pathway converts tryptophan to Indole-3-acetic acid in plants. Mol. Plant 5, 334-338. https://doi.org/10.1093/mp/ssr104 


\section{Figure legends}

FIGURE 1 BPA inhibits primary root growth by reducing the length of the elongation zone and expansin expression in Arabidopsis. (a) Longitudinal views of the wild-type (Col-0) Arabidopsis seedlings grown for 2 weeks on a 1/2 MS agar media supplemented with varying concentrations (0 to $10 \mathrm{ppm}$ ) of BPA. (b) Accumulation levels of BPA in Arabidopsis in (a). (c) Primary root length, (d) the length of the elongation zone, (e) the cell length of the elongation zone, and (f) the longitudinal views of the Arabidopsis seedlings grown for 10 days on the control (1/2 MS) and agar media supplemented with 10 ppm BPA; bar=400 $\mu \mathrm{M}$. (g) Transcript levels of AtEXPA8 and AtEXPA10 determined by qRT-PCR in roots of Arabidopsis seedlings. Data indicate the mean \pm standard error (SE) of three independent experiments. Different letters above the columns represent statistical differences between treatments according to Tukey's multiple comparison test $(\mathrm{p} \leq 0.05)$. For microscopy images, three independent experiments were performed in which at least 10 seedlings were photographed in each treatment, and a representative image has been displayed.

FIGURE 2 BPA inhibits primary root growth by reducing the length of the meristem zone and CYCB1;1 expression in Arabidopsis. (a) The length of the meristem zone. (b) The number of meristem cell. (c) Cell division activity in CYCB1;1::GUS seedlings; bar $=100 \mu \mathrm{M}$. (d, e) Transcript level of AtUPBI in roots of Arabidopsis seedlings, and confocal images showing the YFP fluorescence in roots of $p U P B 1: Y F P$ seedlings (bar=100 $\mu \mathrm{M})$. Data indicate the mean \pm SE $(n=3)$. Different letters above the columns represent statistical differences between treatments (Tukey's test, $\mathrm{p} \leq 0.05$ ).

FIGURE 3 Enhancement of auxin accumulation/distribution by BPA in Arabidopsis. (a) Prolonged ( $8 \mathrm{~h}$ ) GUS staining in roots of DR5::GUS seedlings treated with 0 (1/2 MS control), 
$100 \mathrm{ppb}, 1 \mathrm{ppm}$, and $10 \mathrm{ppm} \mathrm{BPA}$; bar $=100 \mu \mathrm{M}$. (b) GUS staining in roots of 5-day-old DR5::GUS seedlings treated with 10 ppm BPA for $0,6,12$ and $24 \mathrm{~h}$; bar $=100 \mu \mathrm{M}$. (c) Confocal images of DR5rev ::GFP seedlings; bar $=100 \mu \mathrm{M}$. (d) Confocal images of DII-VENUS seedlings; bar $=100 \mu \mathrm{M}$.

FIGURE 4 Reductions of root growth, expansin expression and cell division activity by auxin in Arabidopsis. (a) Primary root lengths of the Arabidopsis seedlings treated without (1/2 MS) and with IAA (100 and $200 \mathrm{nM}$ ) and NAA (100 and $200 \mathrm{nM})$ for 10 days. (b, c) Transcript levels of AtEXPA8 and AtEXPA10 determined by qRT-PCR in the roots of Arabidopsis seedlings grown and treated as in (a). (d) GUS expression in roots of $C Y C B 1 ; 1: \because G U S$ seedlings grown in the presence and absence of $200 \mathrm{nM}$ IAA or NAA; bar $=100 \mu \mathrm{M}$. Data indicate the mean $\pm \mathrm{SE}$ $(n=3)$. Different letters above the columns represent statistical differences between treatments (Tukey's test, $\mathrm{p} \leq 0.05$ ).

FIGURE 5 Modulation of auxin transporter expressions by BPA and root growth inhibitions in auxin transporter mutants. Confocal images of pPIN1::PIN1-GFP (a), pPIN2::PIN2-GFP (b) and $p P I N 4: \because Y F P(\mathrm{c})$, and GUS staining of $p P I N 7: \because P I N 7-G U S(\mathrm{~d})$ and $p P I N 7: \because G U S$ (e), and confocal image of $p A U X 1:: A U X 1-Y F P$ (f) seedlings grown for 5 days on 1/2 MS agar media supplemented without (left) and with 10 ppm BPA (right); bar=100 $\mu \mathrm{M}$. (g) BPA-induced root growth inhibition in wild-type (Col-0) and various auxin transporter mutants. Seven-day-old Col-0 and auxin transporter mutants grown on 1/2 MS agar media were exposed to $10 \mathrm{ppm}$ BPA for $24 \mathrm{~h}$, and the lengths of newly grown roots were measured after growth for an additional 2 days on $1 / 2$ MS media. For each line, the value of root growth in the control condition (1/2 MS) was set as $100 \%$, and the relative value of BPA-treated seedlings was calculated. Data indicate the mean $\pm \operatorname{SE}(n=3)$, and each includes $>30$ seedlings. Asterisks represent significant 
differences between lines in the presence of BPA $(\mathrm{P} \leq 0.05)$. n.s; no significant difference.

FIGURE 6 Treatment with auxin efflux inhibitor (NPA) and influx inhibitor (NOA) restores BPA-induced root growth inhibition, $D R 5$ induction and $C Y C B 1 ; 1$ repression. (a) Primary root length of wild-type (Col-0) Arabidopsis grown for 10 days on media supplemented without and with BPA $(10 \mathrm{ppm})$ in the presence or absence of NPA $(1 \mu \mathrm{M})$ and NOA $(1 \mu \mathrm{M})$. (b) GUS staining in roots of $D R 5: \because G U S$ seedlings treated without and with BPA $(10 \mathrm{ppm})$ in the presence or absence of NPA $(1 \mu \mathrm{M})$ and NOA $(1 \mu \mathrm{M})$ for 5 days; bar=100 $\mu \mathrm{M}$. Graph (right) shows the quantification of the GUS staining. (c) GUS expression in roots of $C Y C B 1 ; 1: \because G U S$ seedlings grown and treated as in (b). Graph (right) is the quantification of the GUS staining. Data indicate the mean $\pm \mathrm{SE}(\mathrm{n}=3)$. Different letters above the columns represent statistical differences between treatments (Tukey's test, $\mathrm{p} \leq 0.05$ ). 
Figure 1

(a)

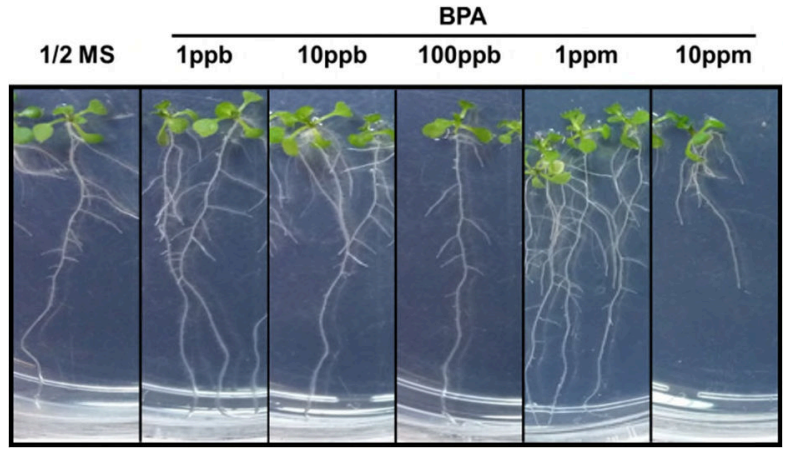

(b)

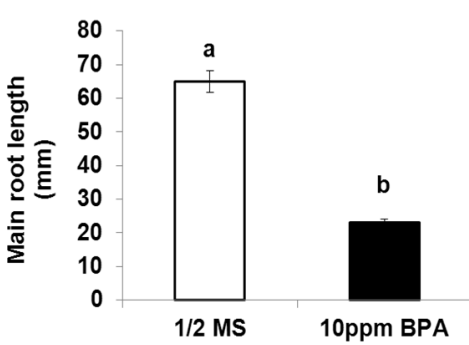

(c)

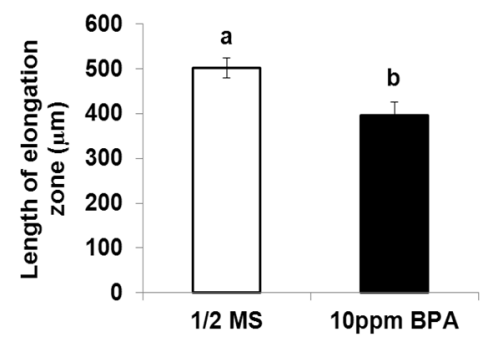

(e)

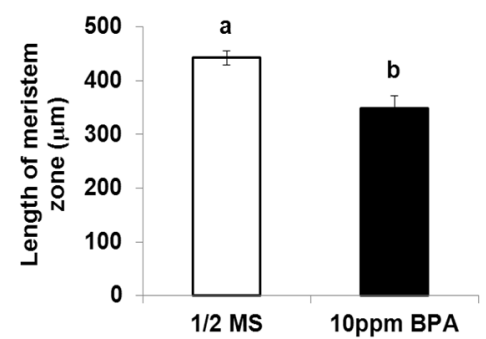

(g)

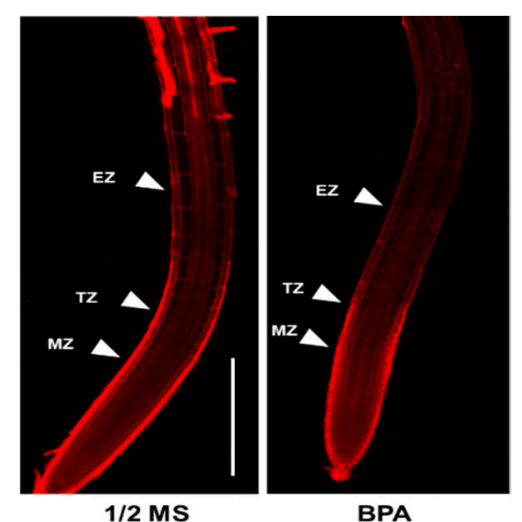

(d)

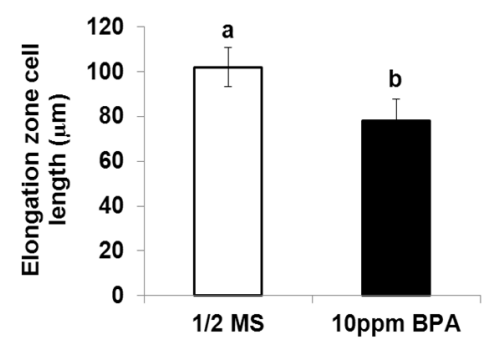

(f)

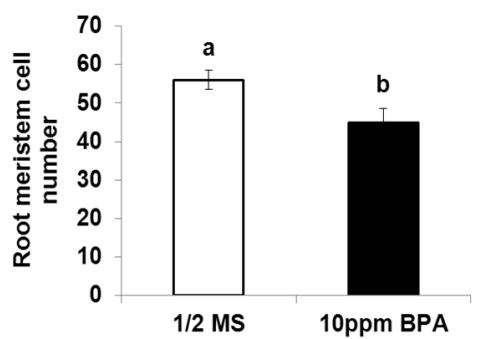

(h)

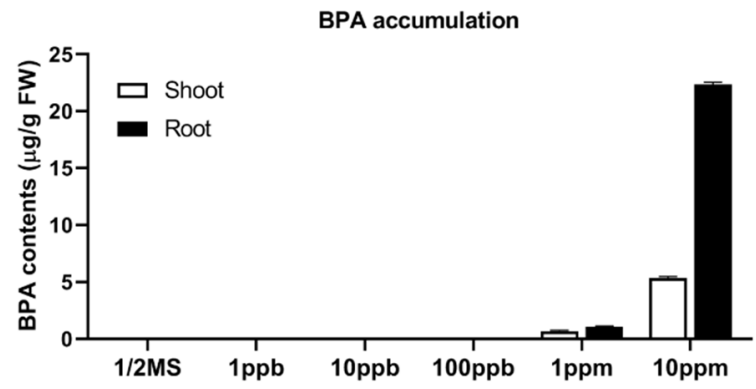


(a)
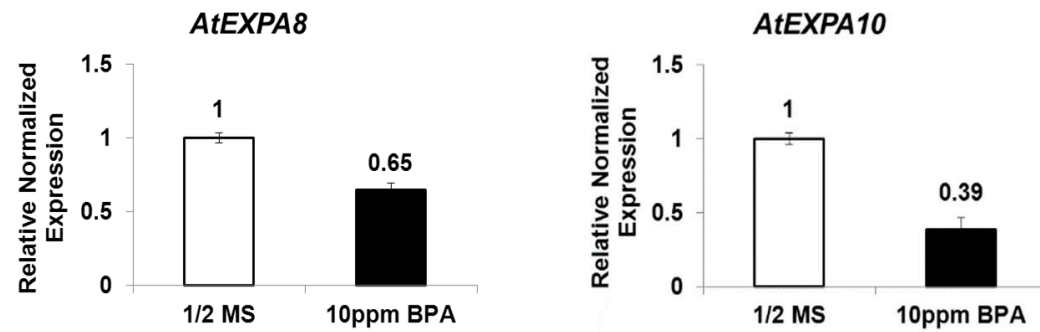

(b)

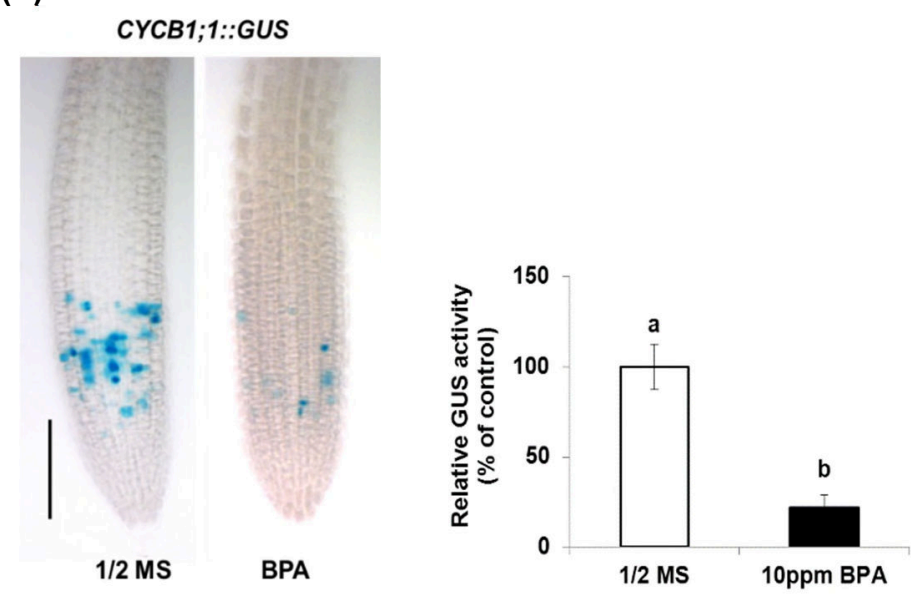

(c)

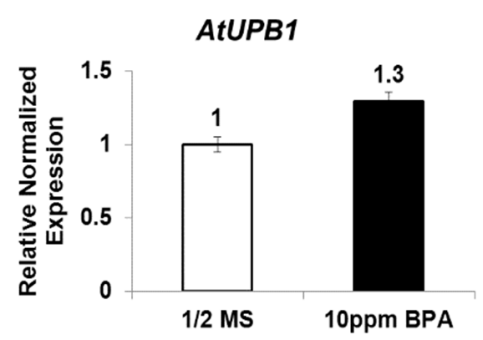

(d)
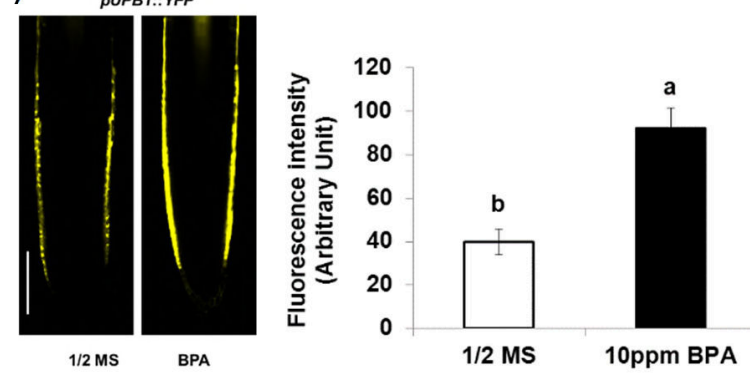
Figure 3

(a)

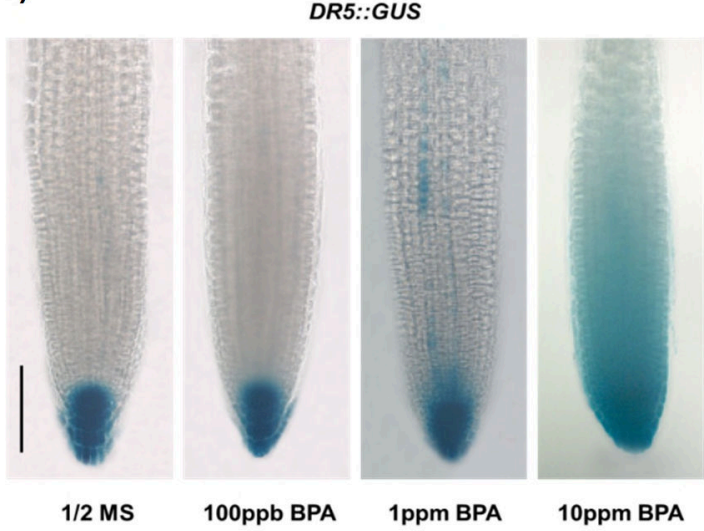

(b)

DR5::GUS

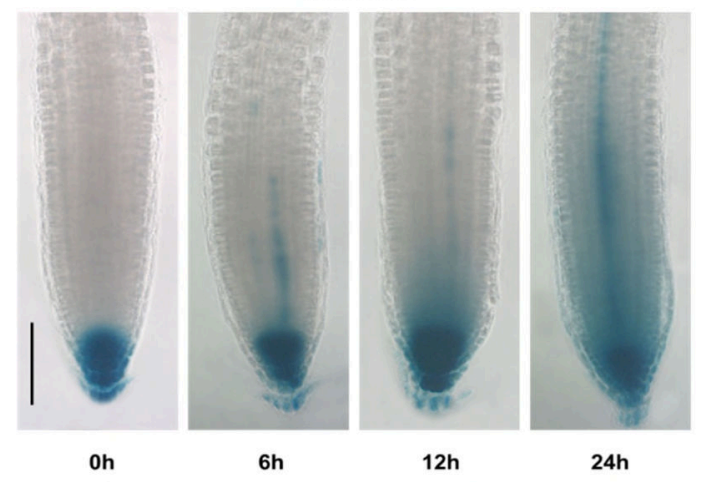

(c)

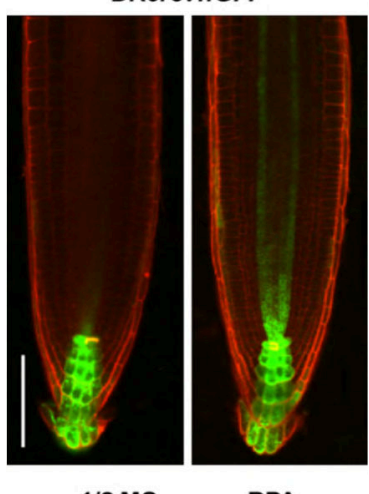

1/2 MS

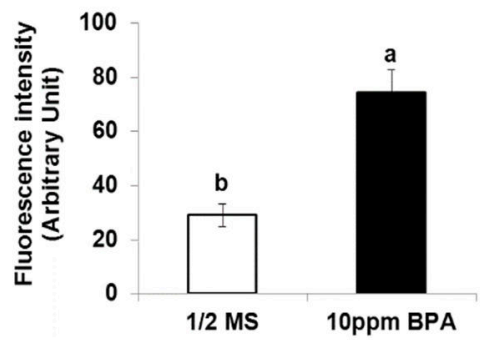

(d)
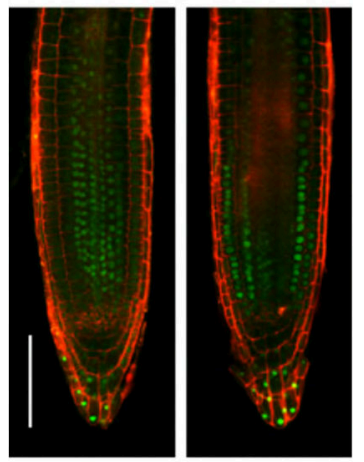

1/2 MS

BPA

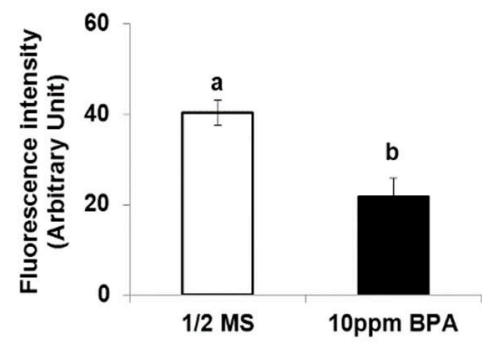


Figure 4

(a)

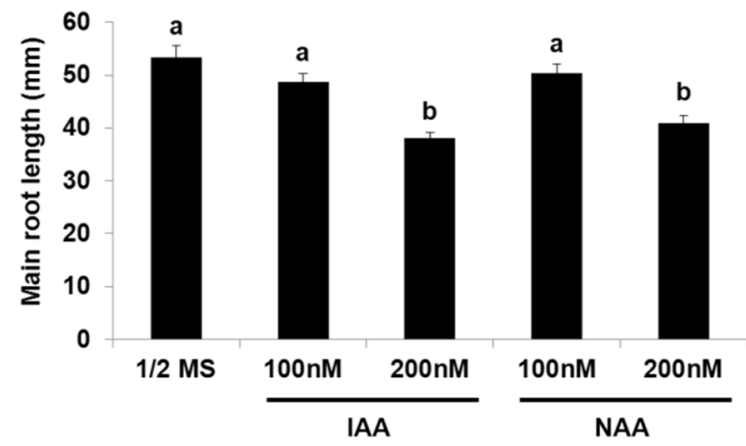

(b)

(c)
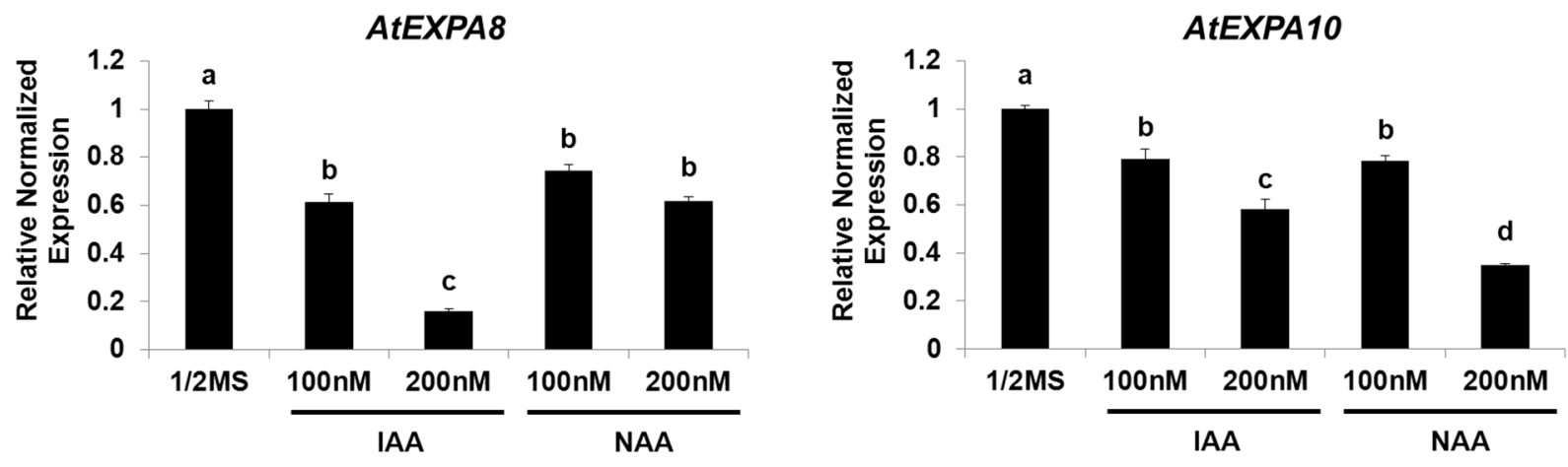

(d)

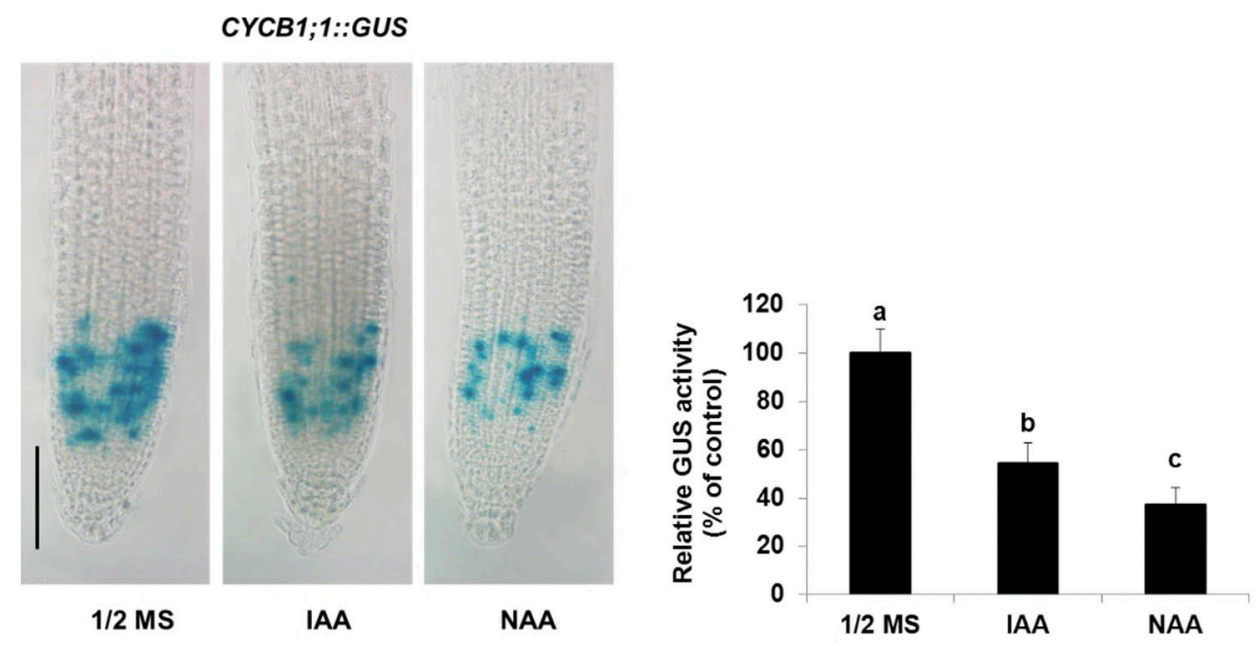


Figure 5

(a)

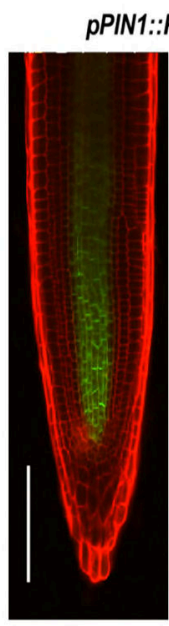

1/2 MS

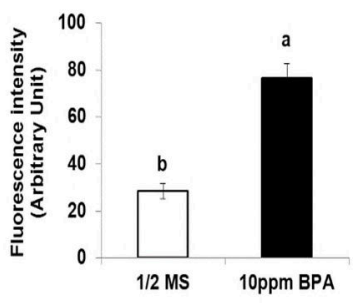

(d)
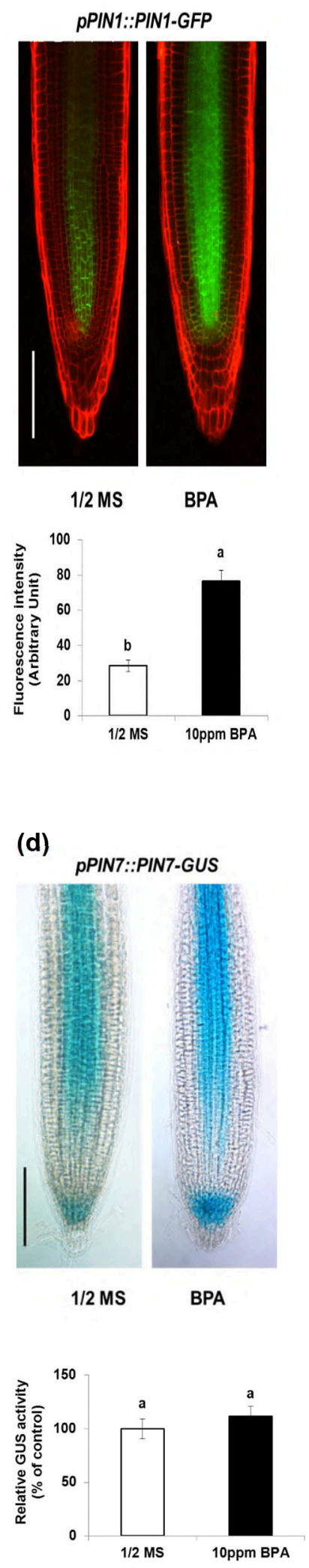

BPA (b)

(e)

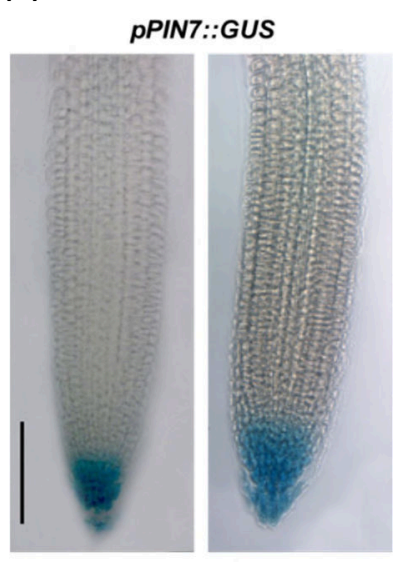

$1 / 2 \mathrm{MS}$

BPA

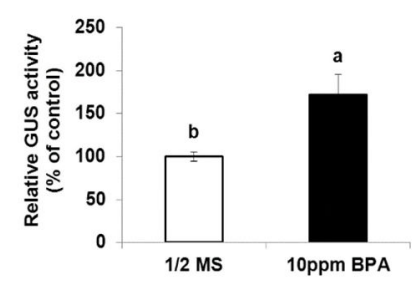

(c)
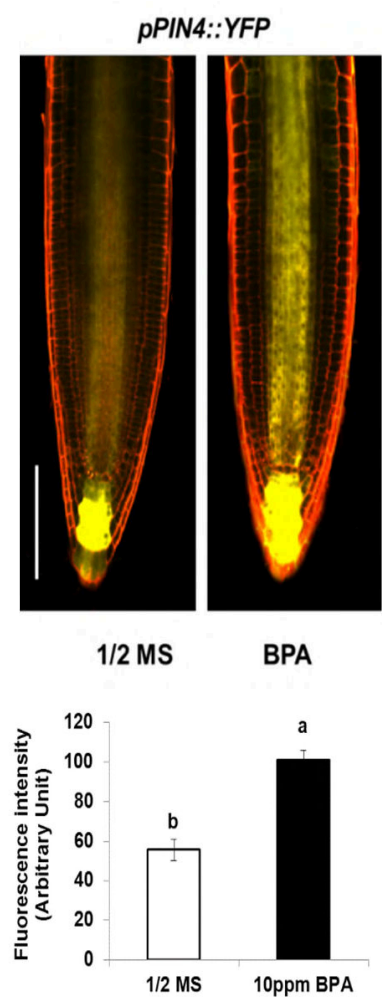

(f)
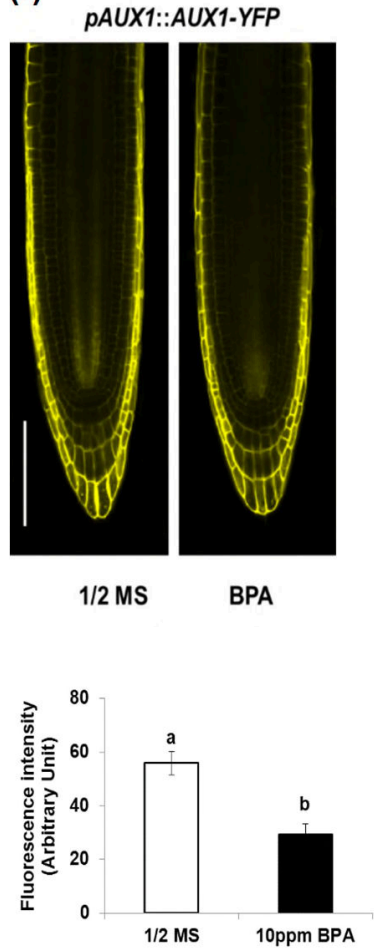
(g) 
Figure 6

(a)

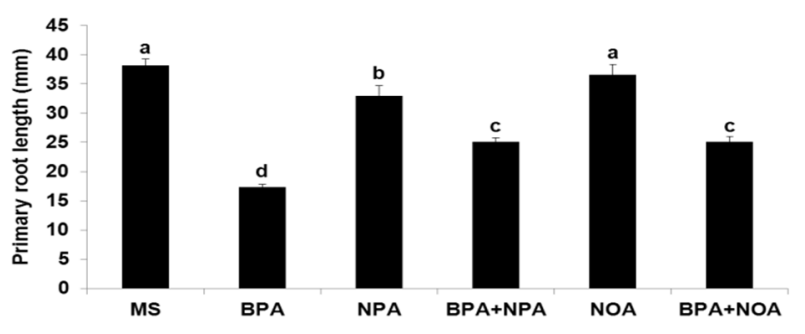

(b)
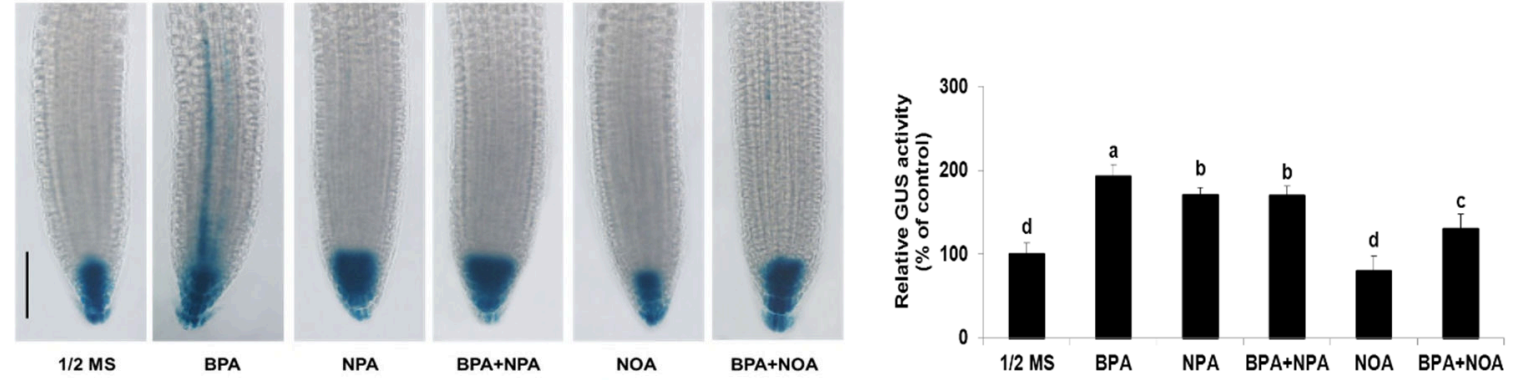

(c)
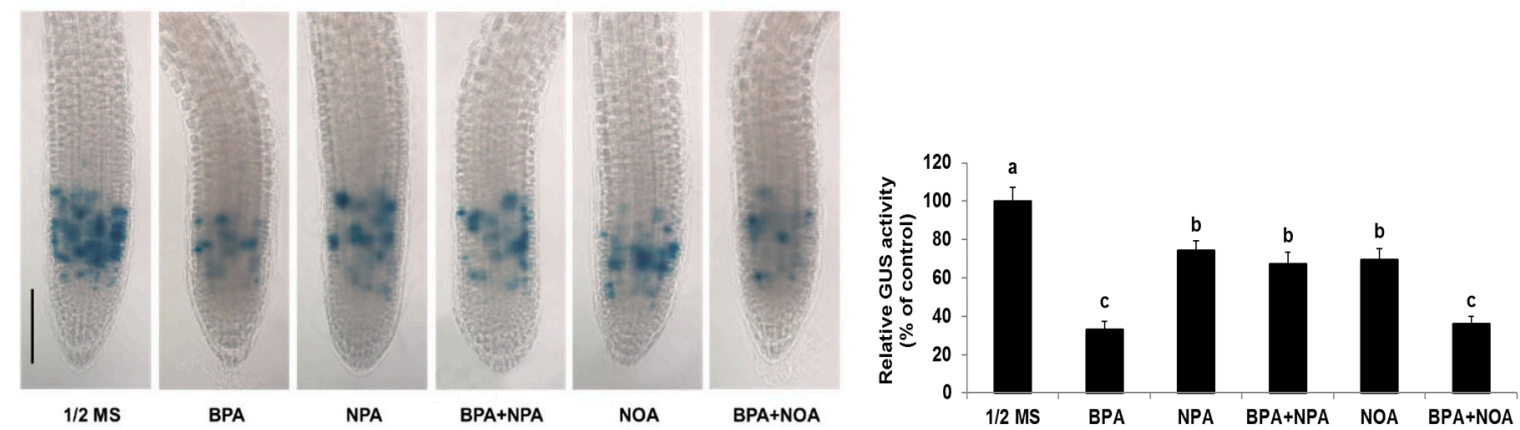
